\title{
2631
}

\section{EXPANSÃO DA EDUCAÇÃO SUPERIOR E PROGRESSIVIDADE DO INVESTIMENTO PÚBLICO}

Joana Costa

Fernando Gaiger Silveira

Roberta Costa

Fábio Waltenberg

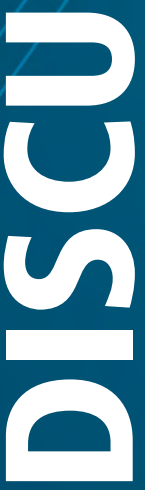

$\frac{1}{a}$

$\frac{0}{1}$ 



\title{
TEXTO PARA DISCUSSÃO
}

Brasília, fevereiro de 2021

\section{EXPANSÃO DA EDUCAÇÃO SUPERIOR E PROGRESSIVIDADE} DO INVESTIMENTO PÚBLICO

\author{
Joana Costa ${ }^{1}$ \\ Fernando Gaiger Silveira² \\ Roberta Costa ${ }^{3}$ \\ Fábio Waltenberg ${ }^{4}$
}

1. Pesquisadora do Ipea. E-mail: <joana.costa@ipea.gov.br>.

2. Pesquisador do Ipea e professor colaborador da Universidade Federal Fluminense (UFF). E-mail: <fernando.gaiger@ipea.gov.br>. 3. Doutoranda no Programa de Pós-Graduação em Economia da UFF. E-mail: <rmendes@id.uff.br>.

4. Professor associado da UFF. E-mail: <fdwaltenberg@id.uff.br>. 


\section{Governo Federal \\ Ministério da Economia \\ Ministro Paulo Guedes}

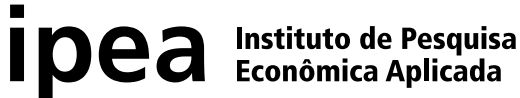

Fundação pública vinculada ao Ministério da Economia, o Ipea fornece suporte técnico e institucional às ações governamentais - possibilitando a formulação de inúmeras políticas públicas e programas de desenvolvimento brasileiros - e disponibiliza, para a sociedade, pesquisas e estudos realizados por seus técnicos.

\section{Presidente}

Carlos von Doellinger

Diretor de Desenvolvimento Institucional Manoel Rodrigues Junior

Diretora de Estudos e Políticas do Estado, das Instituições e da Democracia

Flávia de Holanda Schmidt

\section{Diretor de Estudos e Políticas \\ Macroeconômicas \\ José Ronaldo de Castro Souza Júnior}

Diretor de Estudos e Políticas Regionais, Urbanas e Ambientais

Nilo Luiz Saccaro Júnior

Diretor de Estudos e Políticas Setoriais de Inovação e Infraestrutura

André Tortato Rauen

\section{Diretora de Estudos e Políticas Sociais}

Lenita Maria Turchi

Diretor de Estudos e Relações Econômicas

e Políticas Internacionais

Ivan Tiago Machado Oliveira

\footnotetext{
Assessor-chefe de Imprensa

e Comunicação (substituto)

João Cláudio Garcia Rodrigues Lima

Ouvidoria: http://www.ipea.gov.br/ouvidoria

URL: http://www.ipea.gov.br
}

\section{Texto para Discussão}

Publicação seriada que divulga resultados de estudos e pesquisas em desenvolvimento pelo Ipea com o objetivo de fomentar o debate e oferecer subsídios à formulação e avaliação de políticas públicas.

(C) Instituto de Pesquisa Econômica Aplicada - ipea 2021

Texto para discussão / Instituto de Pesquisa Econômica Aplicada.- Brasília : Rio de Janeiro : Ipea, 1990-

ISSN 1415-4765

1.Brasil. 2.Aspectos Econômicos. 3.Aspectos Sociais. I. Instituto de Pesquisa Econômica Aplicada.

CDD 330.908

As publicações do Ipea estão disponíveis para download gratuito nos formatos PDF (todas) e EPUB (livros e periódicos).

Acesse: http://www.ipea.gov.br/portal/publicacoes

As opiniões emitidas nesta publicação são de exclusiva e inteira responsabilidade dos autores, não exprimindo, necessariamente, o ponto de vista do Instituto de Pesquisa Econômica Aplicada ou do Ministério da Economia.

É permitida a reprodução deste texto e dos dados nele contidos, desde que citada a fonte. Reproduções para fins comerciais são proibidas.

JEL: I0, 121, I23, I24, 128. 


\section{SUMÁRIO}

SINOPSE

ABSTRACT

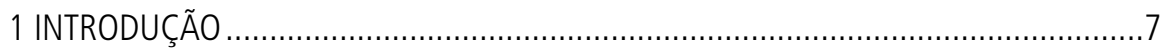

2 EXPANSÃO DA EDUCAÇÃO SUPERIOR NO SÉCULO XXI:

ANTECEDENTES E FATOS ESTILIZADOS

. .9

3 INVESTIMENTO EM ENSINO SUPERIOR PÚBLICO

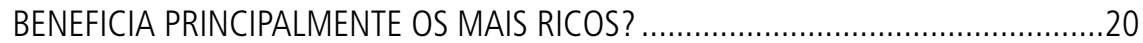

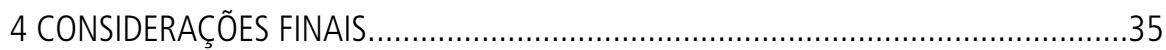

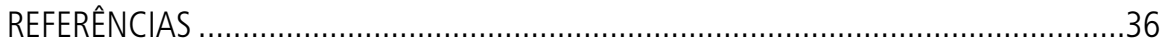





\section{SINOPSE}

Neste trabalho, descrevem-se as mudanças no acesso à educação superior e no perfil do seu alunado, bem como a evolução do impacto redistributivo do investimento em educaçáo superior pública, durante o período 2001-2015, com dados da Pesquisa Nacional por Amostra de Domicílios do Instituto Brasileiro de Geografia e Estatística (PNAD/ IBGE) e do Instituto Nacional de Estudos e Pesquisas Educacionais Anísio Teixeira do Ministério da Educação (Inep/MEC). A expansão da educação superior caminhou rumo a uma maior democratização do acesso especialmente nas universidades públicas e no período 2005-2015. Como resultado, uma proporção maior do investimento do governo em educação superior pública passou a alcançar os estratos mais pobres da sociedade e, além disso, esse nível de educação vem deixando de contribuir para a concentração da renda.

Palavras-chave: desigualdade; educaçáo superior; investimento social.

\section{ABSTRACT}

This paper describes changes that occurred in the Brazilian tertiary education system considering information from household surveys and from administrative data collected by the Ministry of Education. A movement toward democratizing access occurred especially in public universities and in the period 2005-2015. As a result, a higher share

of government investment in public universities has reached socially worse-off strata, and the public investments in tertiary education no longer contribute to increase income inequality.

Keywords: inequality; tertiary education; social investment. 



\section{INTRODUÇÃO}

Certas ou erradas, algumas ideias tornam-se tão arraigadas no imaginário popular, ou mesmo no acadêmico, que somente com grande dificuldade sáo superadas ou substituídas. Uma delas é a de que a educação superior brasileira em geral, mas sobretudo sua vertente pública, é elitista, regressiva, reprodutora e até mesmo fomentadora de desigualdades. Embora essa caracterização em grande medida correspondesse à realidade até o final do século passado (McCowan, 2007), ao longo do início deste século houve importante reversão de tendências, já identificada na literatura, a qual relata - de forma esparsa e com ressalvas - uma redução das desigualdades de oportunidades no acesso à educação superior e uma popularização da composição do alunado, seja nas instituiçóes privadas, seja nas públicas (IBGE, 2016; Oliveira, 2019; Salata, 2018; Caseiro, 2016; Carvalho e Waltenberg, 2015; Brito, 2014).

Os principais objetivos deste trabalho são descrever, de forma sistemática, essas mudanças de acesso e perfil, além da evolução do impacto redistributivo do investimento em ensino superior público, ao longo do período 2001-2015. Para tanto, valemo-nos de informaçôes sobre universitários disponíveis na Pesquisa Nacional por Amostra de Domicílios do Instituto Brasileiro de Geografia e Estatística (PNAD/ IBGE) e também sobre valores de investimento público por aluno fornecidos pelo Instituto Nacional de Estudos e Pesquisas Educacionais Anísio Teixeira do Ministério da Educação (Inep/MEC).

Os resultados mostram que, até 2005, a expansão da educação superior beneficiou principalmente indivíduos pertencentes aos dois quintos mais elevados da distribuição de renda, enquanto, no período 2005-2015, os estratos de renda mais baixos beneficiaram-se consideravelmente. Houve redução do hiato de frequência por área de residência, por cor e por nível educacional da mãe. As universidades públicas acolheram maior proporção de estudantes pobres, que residem em áreas não metropolitanas e que são pretos e pardos. A tendência geral foi de redução das desigualdades de oportunidade de acesso, tornando mais democráticas as universidades públicas e privadas brasileiras. Apesar de todo esse movimento, ao final do período analisado, em 2015, parcela considerável do investimento público em educação superior ainda era apropriada pelos estratos superiores de renda, de modo que ainda faltava muito para uma efetiva igualdade de oportunidades. 
Por sua vez, o estudo do impacto redistributivo do investimento público em educação revela, em primeiro lugar, que, entre 2001 e 2015, houve aumento do investimento público por aluno em todos os níveis de educação, mas que a elevação foi menos intensa na educação superior que na educação básica. Concretamente, a razão entre essas grandezas - que era de 11,0 em 2001 e passou a ser de 3,6 em 2015 - denota tendência de maior progressividade no investimento em educação tomado em seu conjunto. Em segundo lugar, com olhar restrito à educação superior, enquanto, no início do século, a curva de Lorenz da renda mensal domiciliar per capita e a curva da incidência ${ }^{1}$ do investimento em ensino superior público per capita se cruzavam, em 2015 a curva de Lorenz da renda mensal domiciliar per capita passa a ser dominada pela curva da incidência do investimento em ensino superior público per capita, movimento que indica uma regressividade em queda do investimento em educação superior. Enquanto, em 2001, o investimento em educação per capita elevava o índice de Gini em 0,0016, em 2014 e 2015, a contribuição é no sentido de propiciar uma pequena redução, de -0,0002.

Apesar de todas essas mudanças, é persistente a caracterização do elitismo e da injustiça da nossa educação superior (Banco Mundial, 2017), questóes que já não deveriam ter a centralidade que ainda têm. Por isso, um objetivo complementar deste texto é contribuir para um redirecionamento do debate. Nosso sistema de educação superior de hoje não padece dos mesmos problemas e na mesma intensidade que padecia na virada do século. Ainda é preciso manter, e aprofundar, políticas e instrumentos que possibilitaram a mudança de tendência observada no início deste século.

Mas há novos desafios, que requerem mais investigação da academia, e nova dose de criatividade e iniciativa dos formuladores de políticas, tais como: assegurar a permanência no ensino superior de estudantes cujas famílias não fazem parte da elite econômica; melhorar a qualidade da educação superior pública e privada com custos sob controle; e democratizar horizontalmente as universidades, incrementando o acesso e a permanência de alunos de perfil socioeconômico desfavorecido em cursos universitários de elite (como medicina, direito e engenharias). Enquanto o debate educacional estiver emperrado em questôes desatualizadas, esses novos obstáculos a uma educação equitativa de melhor qualidade não receberão a devida atenção.

1. Está denominando-se de curva de incidência do investimento em ensino superior público per capita a curva de concentração do investimento com a ordenação pela renda anterior ao benefício - renda que se denominou de original. 


\section{EXPANSÃO DA EDUCAÇÃO SUPERIOR NO SÉCULO XXI: ANTECEDENTES E FATOS ESTILIZADOS}

\subsection{Contexto institucional e principais achados da literatura}

$\mathrm{Na}$ década de 1990, foi implementado um conjunto de políticas de educação e de proteção social em geral, preconizadas pela Constituição Federal de 1988, como a obrigatoriedade da educação dos 7 aos 14 anos, o Sistema Único de Saúde (SUS) e o Benefício de Prestação Continuada (BPC) regulamentado pela Lei Orgânica da Assistência Social (Loas), ou por iniciativa do Executivo federal, como o Fundo de Manutençáo e Desenvolvimento do Ensino Fundamental e de Valorização do Magistério (Fundef), e o Programa Saúde da Família. Como resultado, no final do século passado, já se observava uma expressiva elevaçáo da frequência escolar na educaçáo básica. Em 2001, a taxa de escolarizaçáo de pessoas de 7 a 14 anos alcançava 96,5\%, contra pouco mais de 80,0\% em 1990 (Carvalho, 2003). Ainda que náo na mesma velocidade, expandia-se também a educação superior brasileira, apoiada no crescimento do setor privado.

As políticas federais de educação e de proteção social avançaram no início do século XX abrangendo uma série de iniciativas, que incluíram o Programa Bolsa Escola Federal, consolidado em seguida por meio do Programa Bolsa Família e o Fundo de Manutenção e Desenvolvimento da Educação Básica (Fundeb). Em 2015, a taxa de escolarização de pessoas de 7 a 14 anos chegava a 98,8\% e a daquelas entre 15 e 17 anos, a 85,0\% (Osório, 2017).

Como esperado, aumentou a pressão de demanda por educação superior, e o governo federal reagiu concebendo diversas políticas destinadas a atendê-la, tanto no setor público, com a expansão do número de instituiçóes federais, de campi e de matrículas ${ }^{2}$ apoiada no Programa de Apoio a Planos de Reestruturação e Expansão das Universidades Federais (Reuni), como no setor privado, assentando-se neste caso sobre programas de bolsas, renúncia fiscal e empréstimos estudantis, como Programa Universidade para Todos (ProUni) e Fundo de Financiamento ao Estudante do Ensino Superior (Fies). Políticas de ações afirmativas, de iniciativa de estados e do governo federal, consubstanciadas especialmente na Lei de Cotas de 2012, também colaboraram para abrir as universidades a um novo público.

2. CGU...(2015) aponta que o "número de vagas de graduação presencial cresceu mais de 100\%, ao passar de 113.263 em 2002 para 245.983 em 2014. Há treze anos, havia 45 universidades federais e 148 campi. Agora, são 63 universidades e 321 campi. A quantidade de cursos aumentou de 2.047 em 2002 para 4.867 em 2014. As matrículas na graduação presencial subiram de 500.459 para 932.263 no mesmo período". 
Para levar a cabo essas políticas, o investimento público em educação precisou aumentar, e o incremento espalhou-se pelos diversos níveis de ensino. Em termos de participação no produto interno bruto (PIB), os investimentos com educação passam de menos de 4,6\% em 2000 para 6,2\% em $2015 .{ }^{3}$ Os investimentos por estudante na educação básica saltam de R\$ 807 em 2000 para R\$2.497 em 2015, enquanto os da educação superior sobem de $\mathrm{R} \$ 8.849$ para $\mathrm{R} \$ 9.084 .{ }^{4} \mathrm{E}$ importante assinalar que a razão entre essas grandezas se reduz de 11,0 em 2001 para 3,6 em 2015. O investimento per capita na educação superior é comumente apontado como regressivo, visto que o estudante do ensino superior apresenta maior nível socioeconômico do que o da educação básica (Banco Mundial, 2017). No entanto, deve-se ressaltar que a queda da razão entre esses investimentos já é indicativa de uma tendência de maior progressividade no investimento em educação como um todo, tema que será retomado na seção 3 .

Também a democratização do perfil universitário constituiu um fator relevante para reduzir a regressividade do investimento em educação superior e elevar a progressividade do investimento educacional total. A subseção 2.2 apresenta indicadores que caracterizam essa mudança de perfil, mas antes é importante mencionar os estudos que já identificaram o ingresso de grupos antes excluídos do ensino superior.

Ao analisar dados dos Censos Demográficos de 1960 a 2010, Brito (2014) registra que a ampliação do acesso à educação superior nesse período ocorreu às custas de uma desigualdade entre classes, grupos raciais e níveis socioeconômicos. Já estudos que incorporam na análise dados da década de 2010 identificam uma ampliação proporcionalmente maior de grupos mais desfavorecidos historicamente. Exemplos de autores desses trabalhos são Caseiro (2016), que analisa dados de 2004 a 2014, e Salata (2018), cujas pesquisas constam do período 1995-2015.

Salata (2018) destaca que, em parte, a redução das desigualdades no ingresso à universidade deve-se ao arrefecimento das iniquidades nas chances de conclusão do ensino médio. Apesar desses avanços, vale notar que a conclusão do ensino médio ainda constitui um gargalo importante para o acesso ao ensino superior especialmente entre o quinto mais pobre (Senkevics e Carvalho, 2020; Simóes, 2019).

3. Dados disponíveis em: <https://bit.ly/2Y0r6LT>.

4. Valores para 2000 calculados com Índice Nacional de Preços ao Consumidor Amplo (IPCA). 
Já ao considerar somente os indivíduos que haviam concluído o ensino médio, Salata (2018) identifica que a redução das desigualdades de origem no acesso à educação superior ocorreu essencialmente entre 2005 e 2015, mas não entre 1995 e 2005. Esse resultado é coerente com o fato de que esse período posterior é caracterizado por uma maior quantidade de políticas facilitadoras da entrada das pessoas com menores níveis socioeconômicos tais como as cotas, o Reuni, o ProUni e o Fies. Corroborando a relevância das políticas nesse período, Carvalho e Waltenberg (2015) identificam uma certa reduçáo da desigualdade de oportunidades no acesso ao ensino superior entre 2003 e 2013. Há, adicionalmente, estudos que mostram evidências de que a política de cotas contribuiu para uma maior diversidade entre estudantes de universidades públicas (Mendes Junior, Souza e Waltenberg, 2016; Francis e Tannuri-Pianto, 2012; Vilela, Menezes-Filho e Tachibana, 2016).

Na comparação entre universidades públicas e privadas, apesar de Salata (2018) não identificar diferenças nas desigualdades de acesso, Brito (2014) identifica que as desigualdades de acesso ao nível superior estáo associadas aos diferenciais em instituiçôes privadas ao longo da década de 2000 (a partir de dados da PNAD/IBGE de 2001, 2005 e 2009). Também IBGE (2016) aponta que há uma maior diversidade no perfil dos estudantes de universidades públicas, pois é maior a proporção de estudantes de estratos de menor renda.

A mudança em características dos universitários de institutos federais também tem sido registrada por meio das cinco ediçôes da Pesquisa Nacional do Perfil Socioeconômico e Cultural dos Estudantes de Graduação das Instituiçóes de Ensino Superior conduzida pela Associação Nacional dos Dirigentes das Instituições Federais de Ensino Superior (Andifes). Constata-se uma mudança na composição por renda, raça/etnia e rede frequentada no ensino médio (se pública ou particular), e identifica-se que cerca de $70 \%$ dos estudantes de instituiçôes federais possuem renda per capita de até 1,5 salário mínimo em 2018 (Franco e Cunha, 2017; Fonaprace, 2019).

Importante destacar, contudo, que mesmo os estudos que identificam uma maior popularizaçâo no acesso ao ensino superior também ressalvam a persistência de desigualdades. Assim, enfatizam a importância da manutençáo de políticas públicas que tenham o objetivo não apenas de expandir, mas de democratizar o acesso (Oliveira, 2019). Além de afetarem a trajetória de estudo e trabalho daqueles que vierem a concluir o ensino superior, tais políticas também apresentam efeitos positivos sobre indicadores econômicos e sociais das localidades beneficiadas pela expansão universitária. Já há efeitos positivos mensurados pela literatura, tais como o aumento da renda e do emprego e a maior dinamização da economia (Rocha et al., 2017; Niquito, Ribeiro e Portugal, 2018; De Faveri, Petterini e Barbosa, 2018). 


\subsection{Evolução do perfil dos estudantes universitários}

A fim de observar a evolução do perfil dos estudantes universitários durante o período de expansão da educação superior no Brasil, recorremos a pesquisas domiciliares da PNAD/IBGE por um período de duas décadas: 1995-2005. A primeira questáo foi compreender se mudou a probabilidade de um jovem brasileiro frequentar a universidade. Para tanto, tomou-se como população-alvo os jovens de 18 a 24 anos que não possuíam ensino superior completo. Complementarmente, a segunda questão foi averiguar se essa eventual mudança operou no mesmo ritmo para diferentes grupos sociais. Ambas as respostas são afirmativas, como se detalha a seguir.

A expansão de vagas no ensino superior resultou em um aumento da proporção de jovens (18-24 anos) que frequentam o ensino superior. O gráfico 1 mostra que, enquanto a expansão entre 1995 e 2005 favoreceu principalmente os dois quintos mais elevados da distribuição de renda, o aumento entre 2005 e 2015 beneficiou também os estratos com renda mais baixa.

GRÁFICO 1

Taxa de frequência líquida de jovens de 18-24 anos no ensino superior (Em \%)

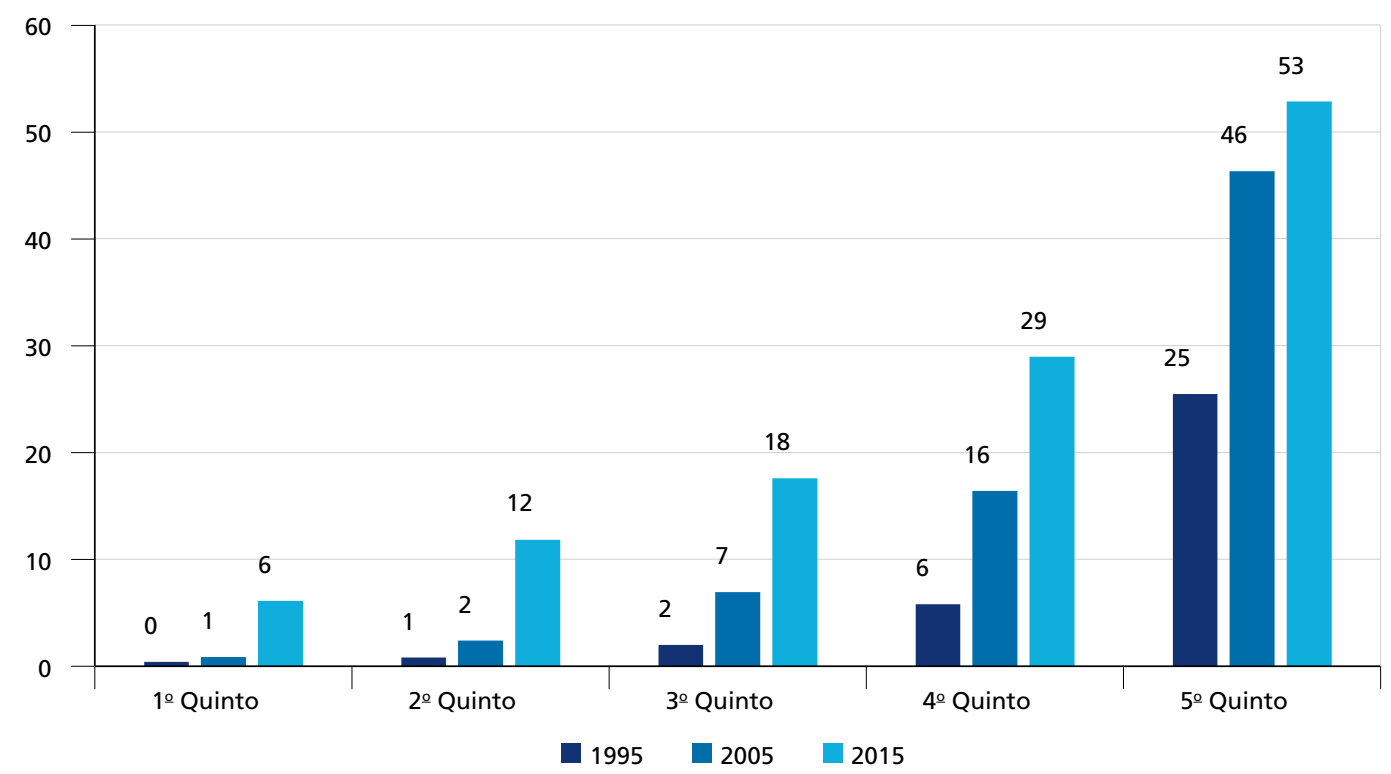

Fonte: Microdados da PNAD/IBGE. 
Para compreender quais as chances de esses jovens cursarem uma universidade pública ou particular, o gráfico 2 disponibiliza a proporçáo de jovens frequentando ensino superior de acordo com a natureza da instituição. Como essa informação só está disponível a partir de 2001, é apresentado o período 2001-2015. Nota-se que houve incremento significativo da proporção de jovens de baixa renda que frequentam universidades, sejam públicas, sejam privadas. Dos jovens de 18-24 anos que estáo entre os $40 \%$ mais pobres, menos de 1\% frequentava a universidade em 2001, contra 9\% em 2015. Destaque-se que o diferencial entre ricos e pobres é menor ao se considerar as universidades públicas (frequentadas por $14,8 \%$ dos jovens do quinto mais rico versus $2,5 \%$ daqueles do quinto mais pobre, uma razão de 5,9) contra as privadas (frequentadas por $38,0 \%$ dos jovens do quinto mais rico versus $3,6 \%$ daqueles do quinto mais pobre, uma razão de 10,4).

GRÁFICO 2

Proporção de jovens de 18-24 anos em universidades, pela natureza da instituição (2001 e 2015) (Em \%)

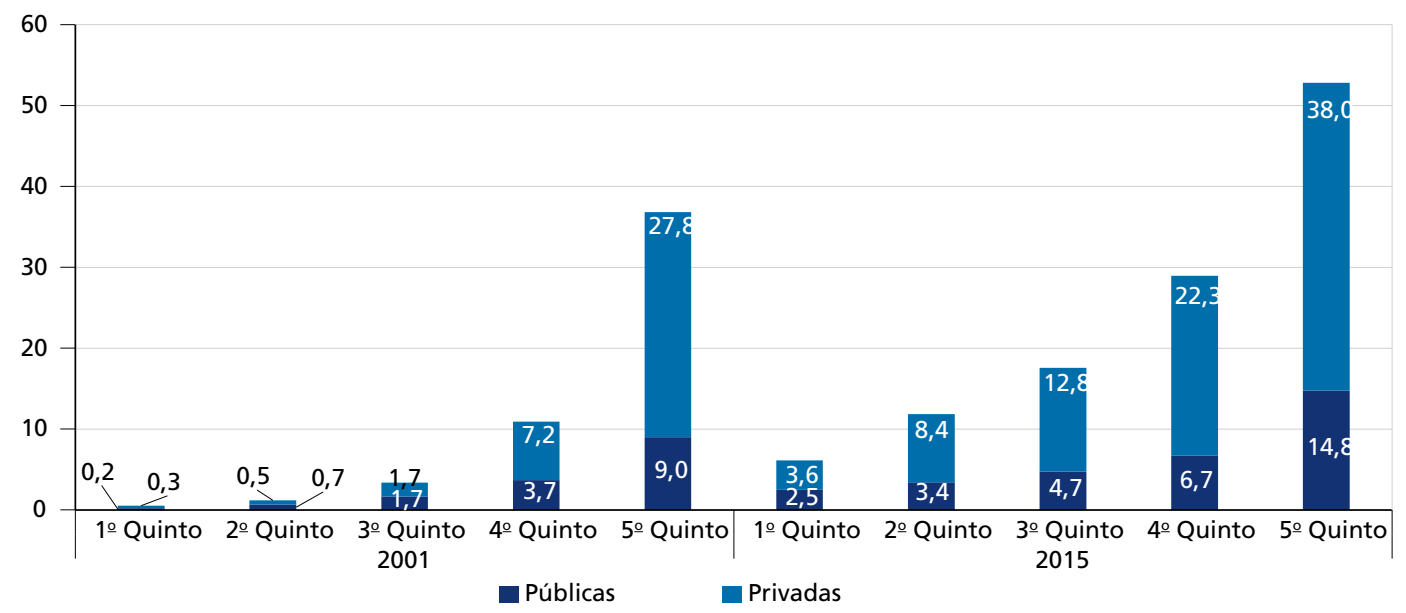

Fonte: Microdados da PNAD/IBGE.

A análise das frequências líquidas no ensino superior por área de residência (gráfico 3), cor (gráfico 4) e nível educacional da mãe (gráfico 5) mostra que houve melhoria para os grupos menos privilegiados, mas que persiste um diferencial ${ }^{5}$ ao longo do tempo. As universidades privadas têm vantagem em termos do número de pessoas de grupos menos privilegiados atendidas por seus serviços. Por exemplo, 9,3\% dos negros de 18-24 anos frequentam universidades privadas em 2015 , enquanto apenas $3,8 \%$ o fazem nas públicas.

5. Vale ressaltar que, na análise dos gráficos 3 a 5 desta subseção, considera-se o diferencial absoluto. No entanto, quando o diferencial absoluto se mantém constante, pode ser observada uma redução do diferencial relativo das proporções. 
Em contrapartida, a diferença absoluta entre os grupos é menor ao considerar universidades públicas. De novo, tomando cor como exemplo, pouco mais de 19,4\% dos brancos frequentam as privadas, mais que o dobro da proporçáo dos negros; nas públicas, os números são 7,2\% e 3,8\%, abaixo do dobro. Já o hiato de frequência entre residentes em cidades metropolitanas e não metropolitanas, que já era pequeno nas universidades públicas em 2001, praticamente desaparece em 2015 (gráfico 3).

\section{GRÁFICO 3}

Proporção de jovens de 18-24 anos em universidades, de acordo com área de residência (2001-2015)

(Em \%)

$3 \mathrm{~A}$ - Privadas

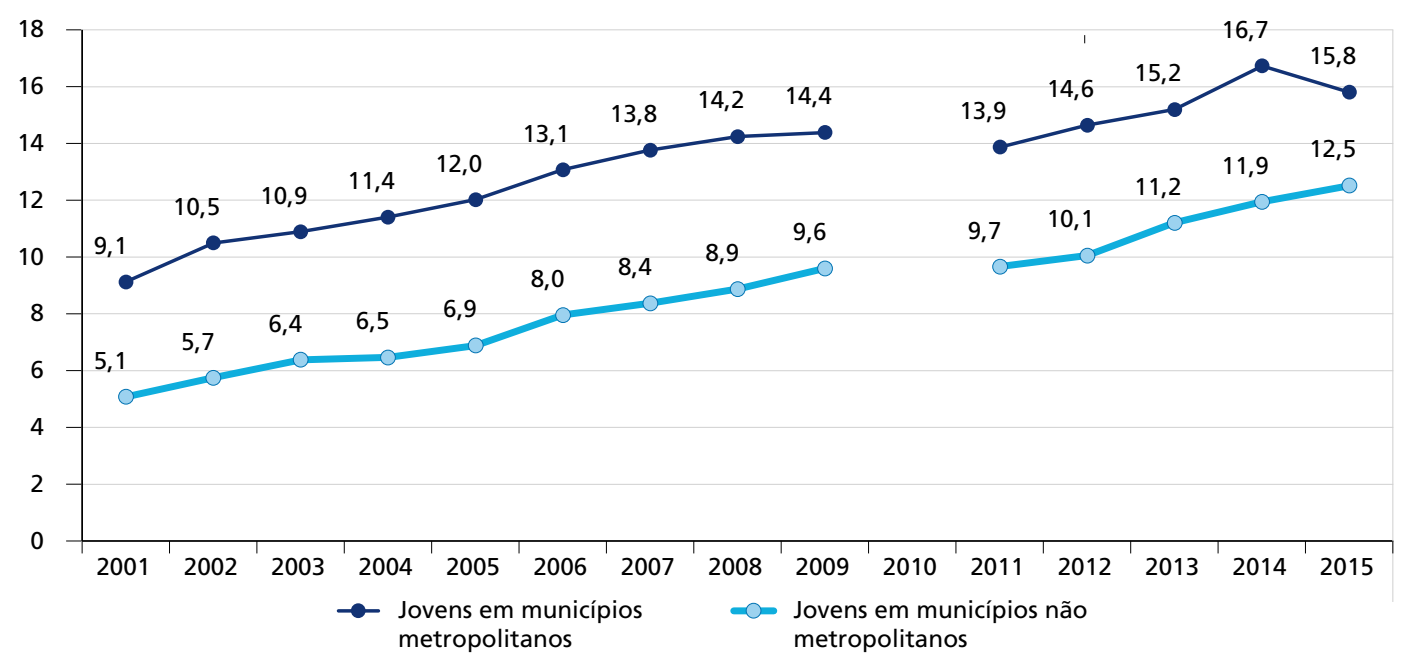

3B - Públicas

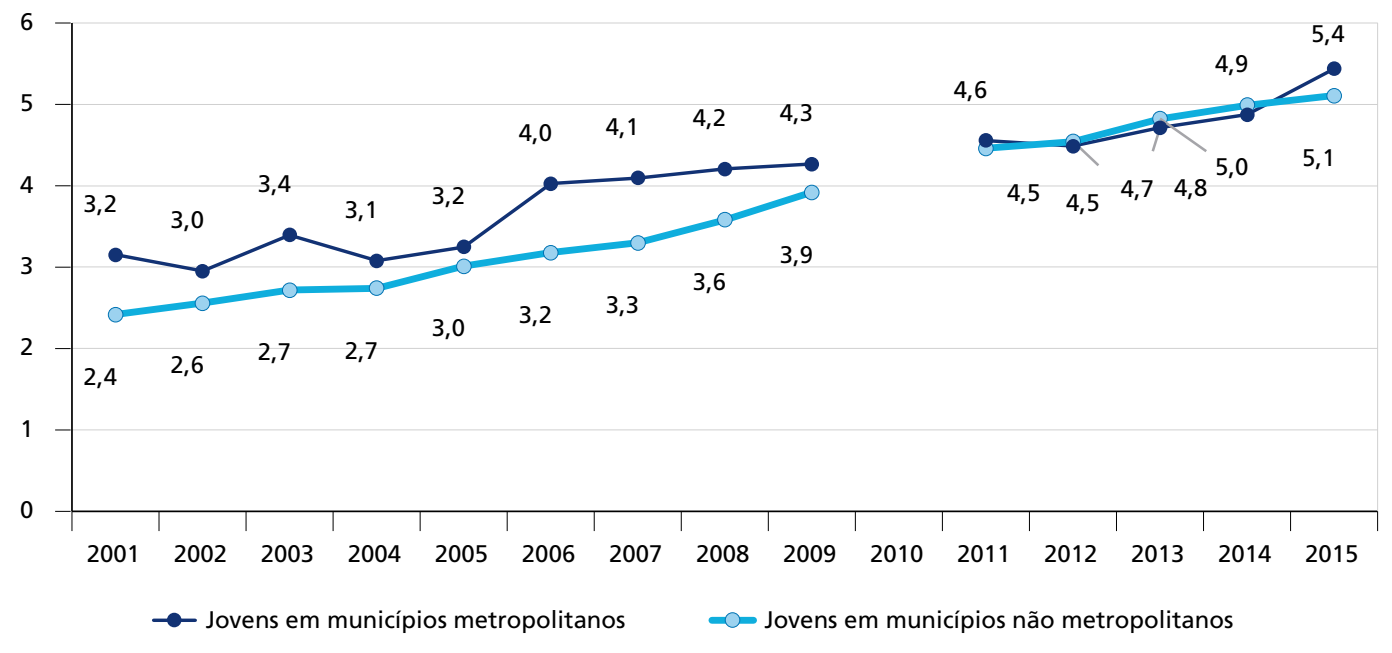

Fonte: Microdados da PNAD/IBGE. 
Texto para

Discussão

GRÁFICO 4

Proporção de jovens de 18-24 anos em universidades, de acordo com cor declarada (2001-2015)

(Em \%)

$4 \mathrm{~A}$ - Privadas

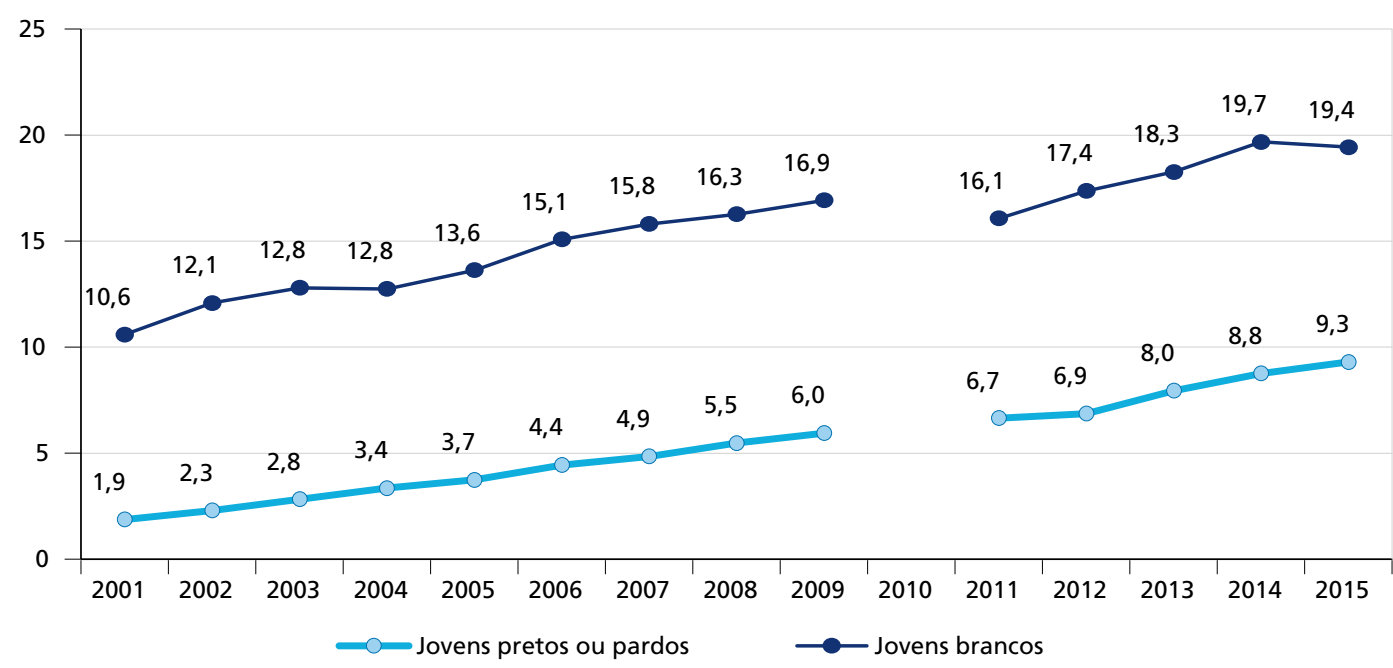

4B - Públicas

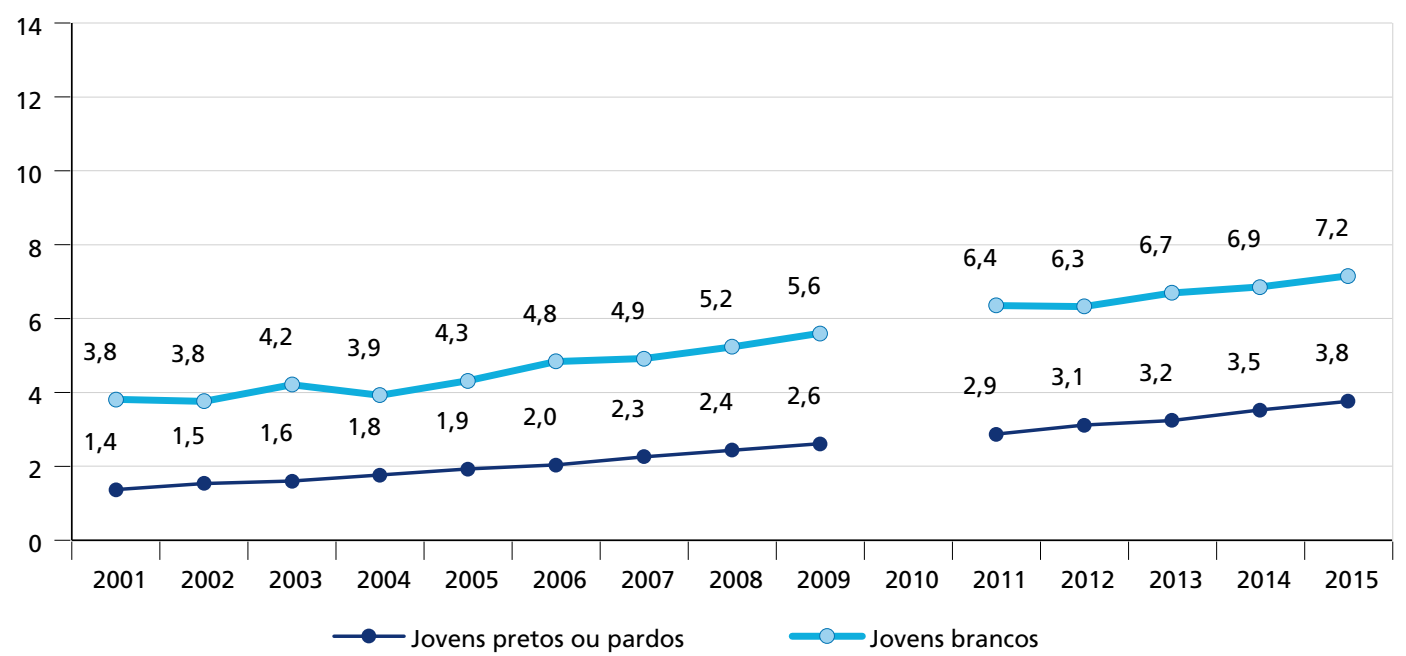

Fonte: Microdados da PNAD/IBGE. 


\section{GRÁFICO 5}

Proporção de jovens de 18-24 anos em universidades, de acordo com o nível de escolaridade materno - considerados apenas jovens que residem com a mãe (2001-2015)

(Em \%)

$5 \mathrm{~A}-$ Privadas

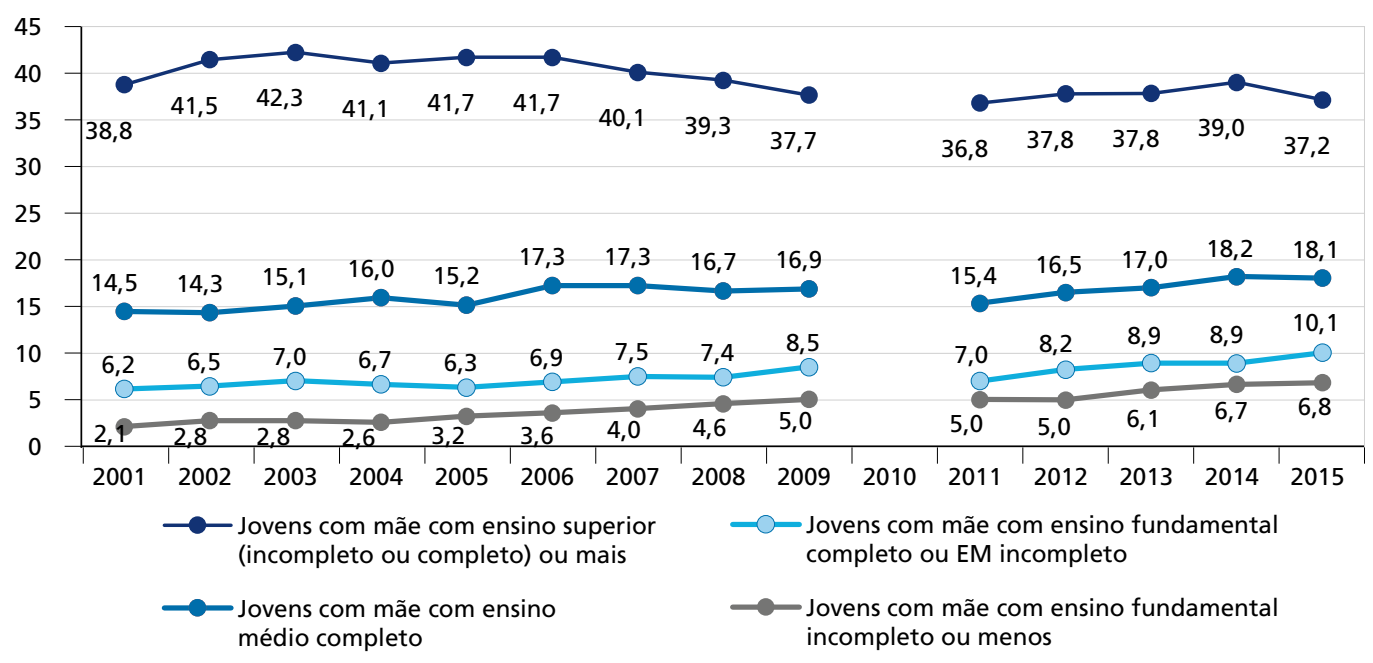

5B - Públicas

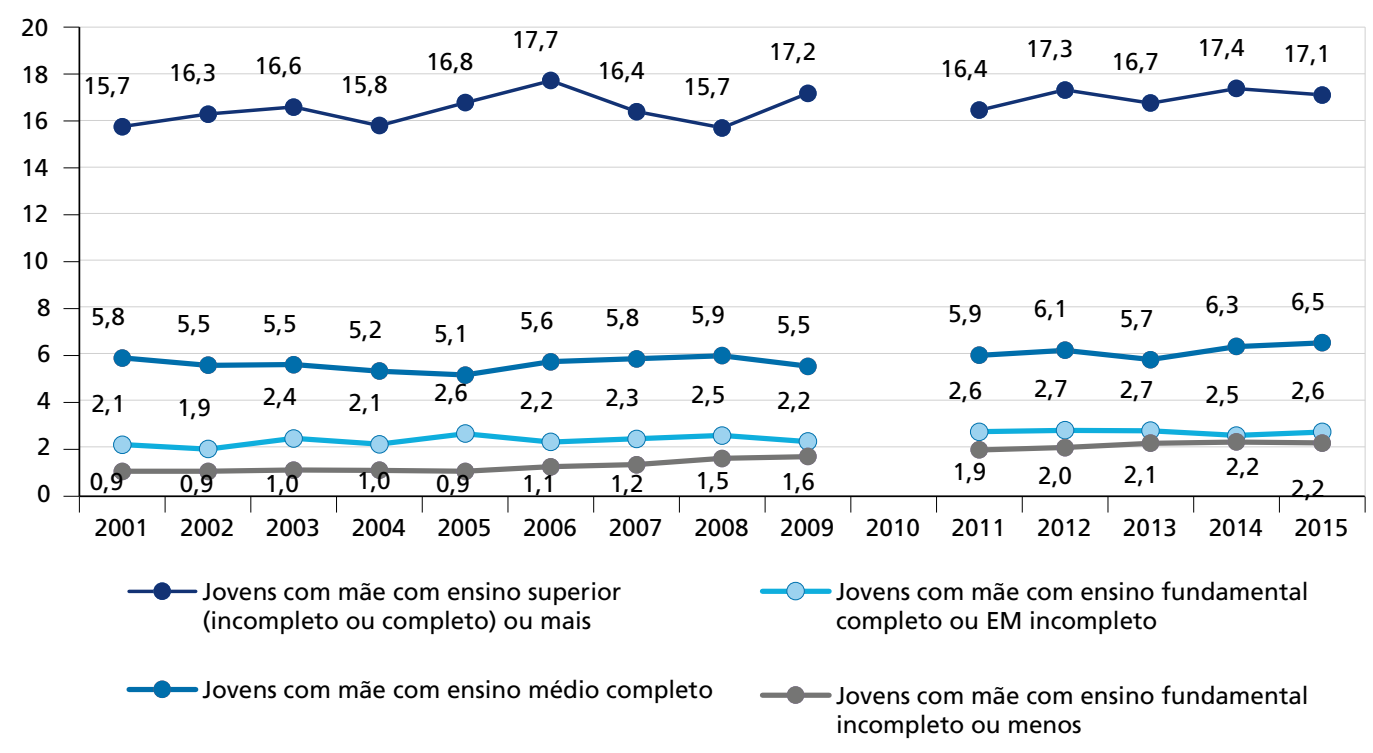

Fonte: Microdados da PNAD/IBGE.

A segunda questão investigada diz respeito à composição dos estudantes, levando a análise a focar nos jovens de 18 a 24 anos que frequentam o ensino superior. 
Tendo em vista a ampliação do acesso às universidades, houve uma mudança no perfil dos estudantes universitários ao longo dos anos analisados. A alteração se caracteriza por um aumento da participaçáo de alunos com renda domiciliar mais baixa e uma redução daqueles com renda mais elevada. Especificamente, o gráfico 6 mostra uma redução na participação dos 20\% mais ricos da população brasileira desde 2001 e um aumento considerável entre os $40 \%$ mais pobres, principalmente a partir de 2005 .

Vale notar que, ao final do período analisado, as universidades públicas, quando comparadas às universidades privadas, apresentam uma maior proporção dos estudantes de renda mais baixa em sua composição, indicando que tal tipo de instituição propicia um acesso mais democrático e menos elitizado (gráfico 7).

\section{GRÁFICO 6}

Composição percentual dos estudantes de universidades públicas ou privadas por quintos de renda domiciliar per capita (Em \%)

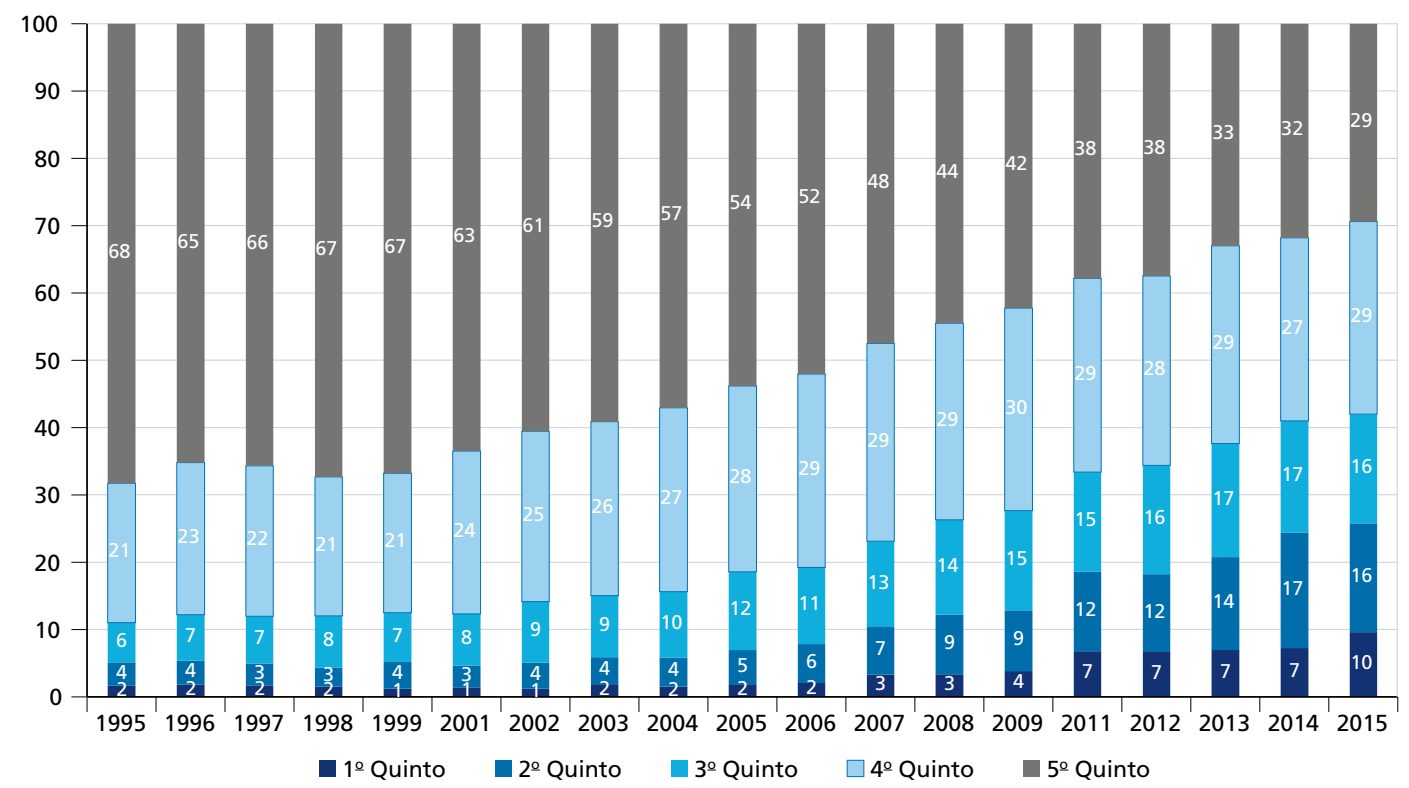


GRÁFICO 7

Composição percentual dos estudantes de universidades privadas e públicas por quintos de renda domiciliar per capita

(Em \%)

$7 \mathrm{~A}$ - Privadas

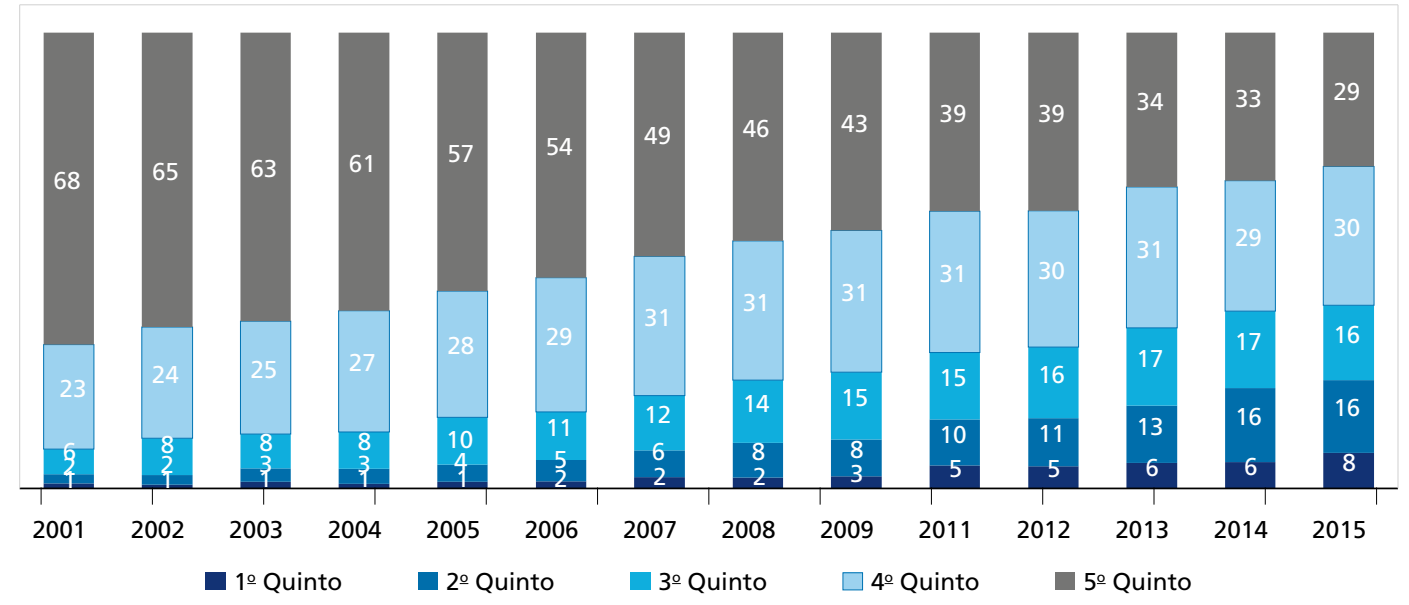

7B - Públicas

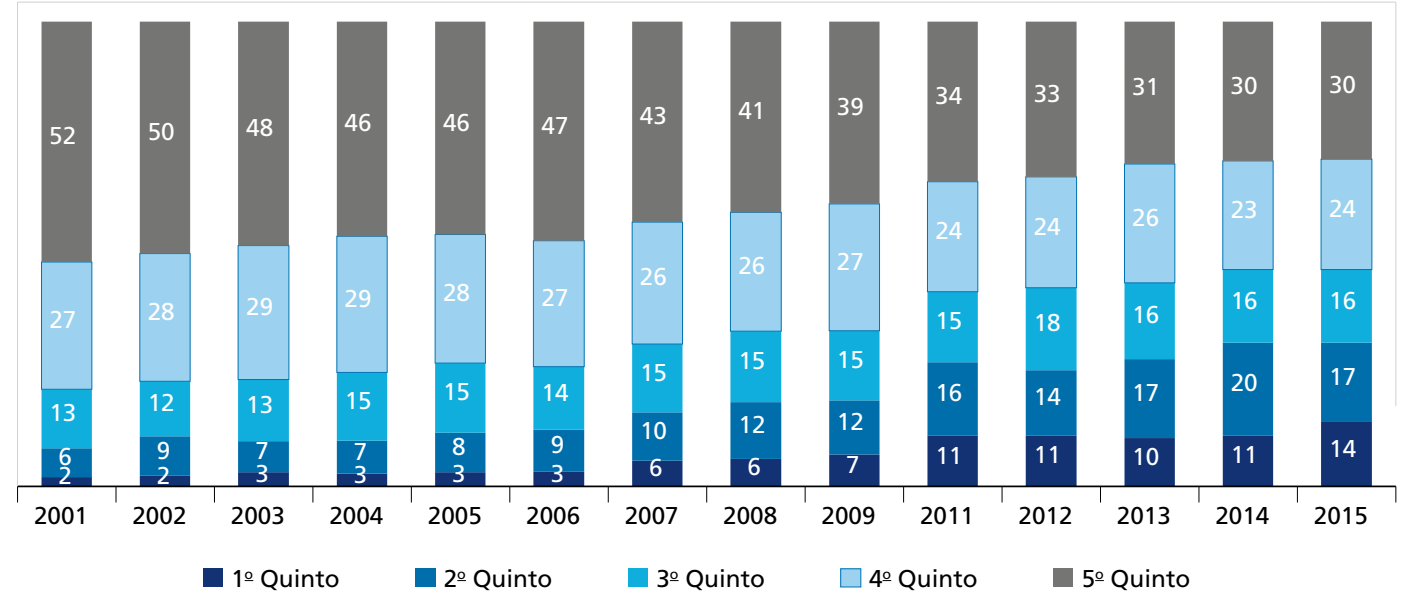

Fonte: Microdados da PNAD/IBGE.

Ao analisar a composição dos universitários por cor e área de residência (gráfico 8), observa-se um aumento na proporção de estudantes residentes em áreas não metropolitanas e também um notável incremento na proporção de pretos ou pardos entre os estudantes. Apesar das mudanças observadas tanto em universidades públicas quanto nas privadas, são as universidades públicas que apresentam maior proporção de estudantes que residem em áreas não metropolitanas e que são pretos ou pardos (gráfico 9). 
GRÁFICO 8

Composição dos estudantes universitários por área de residência ou por cor - universidades públicas ou privadas

(Em \%)

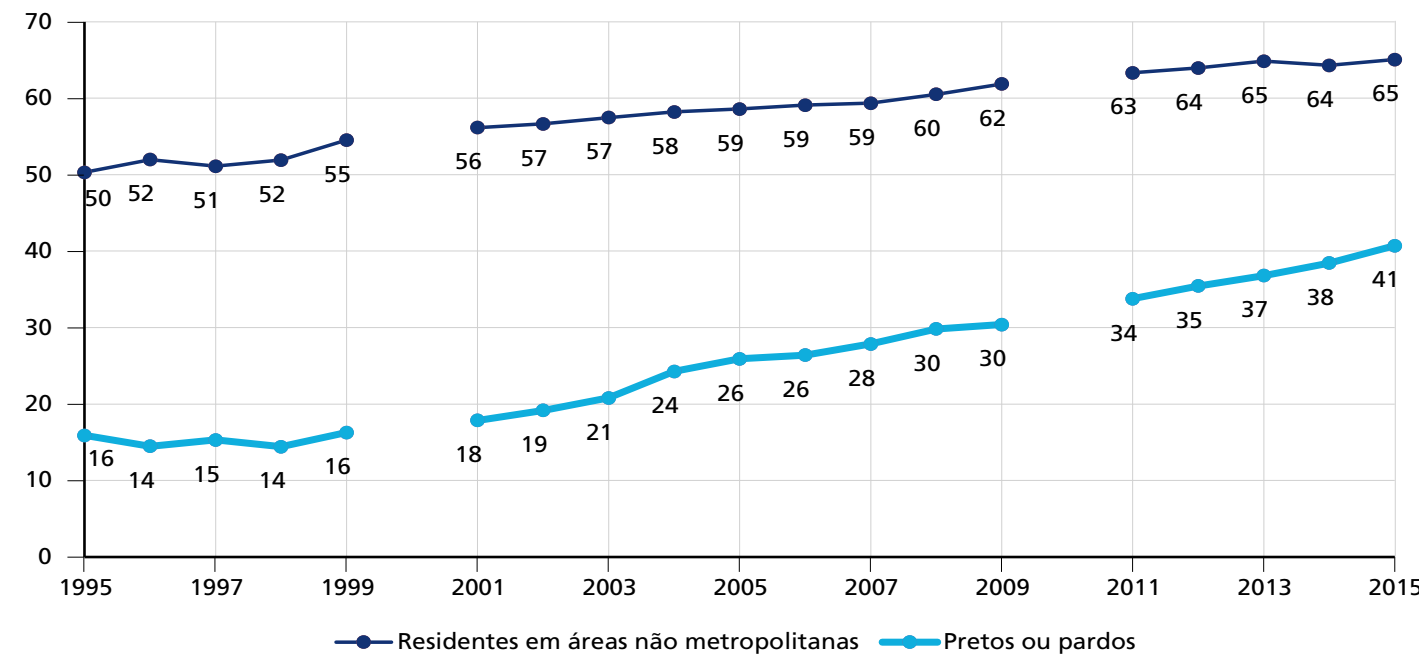

Fonte: Microdados da PNAD/IBGE.

GRÁFICO 9

Composição dos estudantes universitários por área de residência, por cor e pela natureza da instituição (2001-2015)

(Em \%)

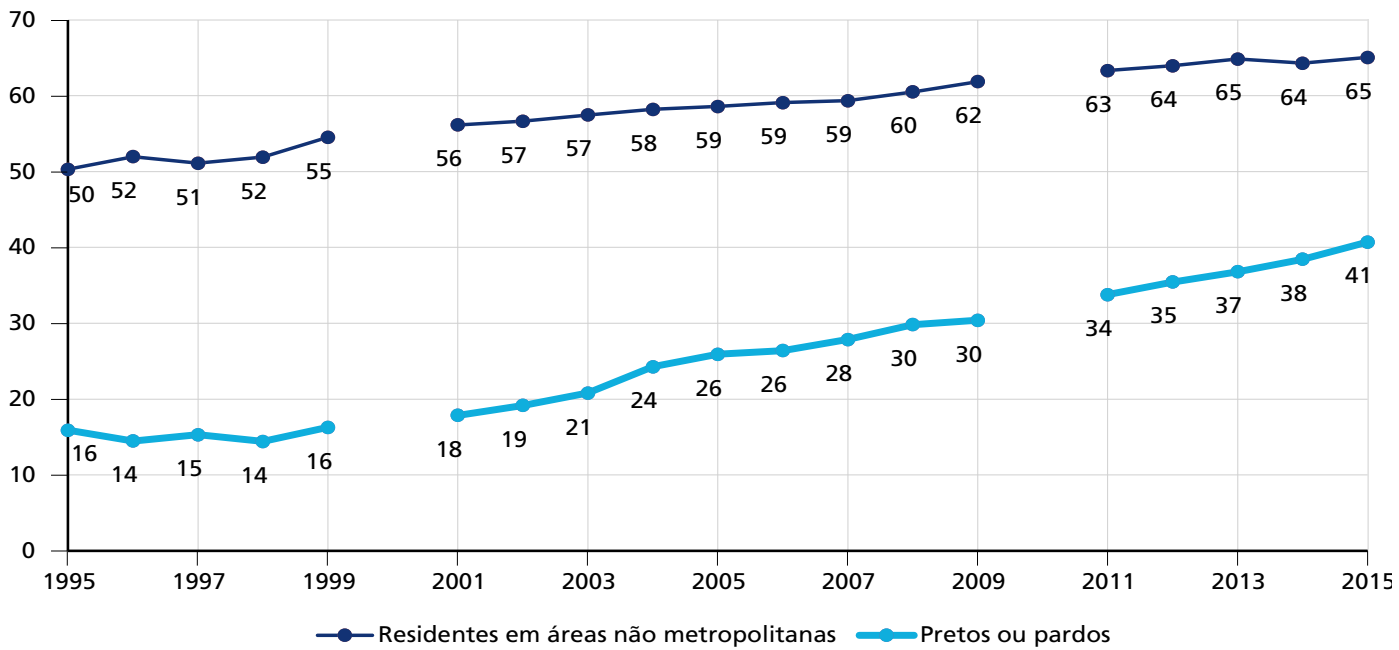

Fonte: Microdados da PNAD/IBGE. 
Em suma, apesar de haver uma persistência da desigualdade, tanto os dados quanto a literatura apresentada nesta seção indicam democratização no acesso ao ensino superior, especialmente no período 2005-2015. Como já discutido, esse período se caracteriza pela combinação de políticas públicas, tais como o ProUni, o Fies, as cotas em universidade públicas e a expansão das vagas em universidades públicas (Reuni). ${ }^{6}$ Também fica evidenciado que, nas universidades públicas, há uma maior diversidade dos perfis dos estudantes. Tendo em vista essa inclusão social ocorrida no acesso à universidade, discute-se a seguir em que medida o investimento público com o ensino superior ainda deve ser considerado como um recurso destinado essencialmente aos indivíduos no topo da distribuição de renda.

\section{INVESTIMENTO EM ENSINO SUPERIOR PÚBLICO BENEFICIA PRINCIPALMENTE OS MAIS RICOS?}

\subsection{Bases de dados e metodologia}

O Inep estima o investimento anual por aluno, segundo níveis de ensino, nas instituições públicas de ensino. As despesas com pessoal ativo, encargos sociais, outras despesas correntes e investimentos financeiros, relativos às três esferas de governo, são as rubricas consideradas na estimativa do investimento médio por aluno, estando excluídas as despesas com aposentadorias e pensôes, bolsas de estudo, financiamento estudantil e juros, amortizaçôes e encargos da dívida da área. Esses dados estão disponíveis para o período de 2000-2015. ${ }^{7}$

Aplicando-se o investimento por aluno às pessoas que frequentam instituiçôes públicas, é possível atribuir valores à provisão pública em educação. Especificamente, para cada ano, o investimento anual por aluno foi dividido por doze, gerando o investimento mensal por aluno. Na sequência, esse valor foi atribuído a cada aluno cursando o ensino superior em uma instituiçáo pública para cada ano da PNAD entre 2001 e 2015. Não foram considerados alunos de pós-graduação. $\mathrm{O}$ investimento mensal do(s) aluno(s) foi dividido pelos membros dos domić́lios, a fim de alcançar o investimento (transferência)

6. Para uma discussão detalhada sobre o ProUni e o Fies, incluindo suas limitações e o perfil dos alunos que os acessam, ver Cataldo (2019).

7. Dados disponíveis em: <https://bit.ly/2Yor6LT>. 
mensal domiciliar per capita em educação pública superior, que, por sua vez foi somado à renda mensal domiciliar per capita. Dessa forma, foi possível obter a nova renda mensal domiciliar per capita que incorpora o investimento em educação superior pública.

A tabela 1 apresenta o investimento público mensal por aluno (coluna A), a populaçáo de estudantes no ensino superior público, segundo a PNAD e o Inep (colunas $\mathrm{B}$ e C), e o investimento total anual estimado, com a PNAD, e o realizado (Inep), com os valores deflacionados pelo IPCA para reais de dezembro de 2019. Com exceção de poucos anos (2001, 2006 e 2007), os dados da PNAD sempre apresentam um número menor de alunos matriculados que o Censo da Educação Superior. No período recente, de 2008 em diante, a subenumeração da população de universitários pela PNAD encontra-se ao redor de $20 \%$. Fala-se em subenumeração, uma vez que se considera que o registro administrativo (Censo Educação Superior do Inep/MEC) tem caráter censitário e, assim, são dados mais precisos sobre matrículas no ensino superior. Entretanto, há de se considerar que os números de matrícula do Censo de Educação Superior podem estar ampliados devido ao fato de que um indivíduo pode possuir mais de uma matrícula.

A subenumeração implica que o exercício apresentado aqui provavelmente subestima os efeitos redistributivos, dado que, como se verá, a importância do investimento na renda é fator que potencializa a progressividade do benefício. Isso acarreta um menor valor total como resultado da aplicação do investimento público e, portanto, uma participação menor na renda, fator de ponderação dos efeitos da incidência ou da concentração do benefício na desigualdade. ${ }^{8}$

Há dois fatos relevantes a serem notados na tabela 1 . O primeiro é que o investimento por aluno, grosso modo, preservou-se em termos reais, com valores reduzidos no biênio 2003-2004, mas retornando ao patamar inicial na presente década, da ordem de R \$ 2.300 mensais em valores de dezembro de 2019. De outra parte, houve um crescimento expressivo do alunado nas instituiçóes públicas de ensino superior: de 73\%, pela PNAD, e de 108\%, segundo o Inep. Logo, o investimento anual em educação superior pública teve um incremento significativo, semelhante ao crescimento da população discente.

8. Como se desconhece a distribuição da subenumeração, na verdade não se pode afirmar que se subestimam ou superestimam os efeitos. Contudo, se considerar que o perfil da população subenumerada é similar à apurada, pode-se afirmar que os efeitos estão subestimados. 
TABELA 1

Investimento público médio mensal por aluno do ensino superior, população universitária do setor público e investimento anual com ensino superior público - Brasil

\begin{tabular}{|c|c|c|c|c|c|c|}
\hline \multirow[b]{2}{*}{ Ano } & \multirow{2}{*}{$\begin{array}{c}\text { Investimento público mensal por aluno } \\
\text { (A) } \\
\text { (R\$ dez. 2019) }\end{array}$} & \multicolumn{3}{|c|}{ Alunos } & \multicolumn{2}{|c|}{$\begin{array}{l}\text { Investimento anual } \\
\text { (R\$ milhões dez. 2019) }\end{array}$} \\
\hline & & $\begin{array}{c}\text { PNAD } \\
\text { (B) } \\
(\mathrm{R} \$ \text { dez. 2019) }\end{array}$ & $\begin{array}{c}\text { Inep } \\
\text { (C) } \\
\text { (R\$ dez. 2019) }\end{array}$ & $\begin{array}{c}\text { Diferença } \\
(\mathrm{C} / \mathrm{B}) \\
(\%)\end{array}$ & $\begin{array}{l}\text { Estimado } \\
(A \times B \times 12)\end{array}$ & $\begin{array}{l}\text { Realizado } \\
(A \times C \times 12)\end{array}$ \\
\hline 2001 & 2.304 & 966.390 & 939.225 & -3 & 26.718 & 25.968 \\
\hline 2002 & 2.134 & 998.245 & 1.051 .655 & 5 & 25.558 & 26.925 \\
\hline 2003 & 1.864 & 1.113 .385 & 1.136 .370 & 2 & 24.901 & 25.414 \\
\hline 2004 & 1.765 & 1.071 .638 & 1.178 .328 & 10 & 22.701 & 24.962 \\
\hline 2005 & 1.901 & 1.167 .233 & 1.192 .189 & 2 & 26.629 & 27.198 \\
\hline 2006 & 1.967 & 1.243 .308 & 1.209 .304 & -3 & 29.351 & 28.549 \\
\hline 2007 & 2.080 & 1.250 .888 & 1.240 .968 & -1 & 31.223 & 30.976 \\
\hline 2008 & 1.922 & 1.276 .561 & 1.552 .953 & 22 & 29.440 & 35.815 \\
\hline 2009 & 2.158 & 1.305 .073 & 1.523 .864 & 17 & 33.796 & 39.462 \\
\hline 2011 & 2.445 & 1.483 .963 & 1.773 .315 & 19 & 43.533 & 52.021 \\
\hline 2012 & 2.221 & 1.479 .035 & 1.897 .376 & 28 & 39.423 & 50.573 \\
\hline 2013 & 2.485 & 1.521 .022 & 1.932 .527 & 27 & 45.355 & 57.625 \\
\hline 2014 & 2.389 & 1.594 .110 & 1.961 .002 & 23 & 45.699 & 56.217 \\
\hline 2015 & 2.291 & 1.670 .045 & 1.952 .145 & 17 & 45.916 & 53.673 \\
\hline
\end{tabular}

Fontes: Sinopse Estatística da Educação Superior/Inep; e microdados da PNAD/IBGE.

Obs.: Valores deflacionados pelo IPCA.

Segundo a tabela 2, ao acrescentarmos o investimento com ensino superior, a renda mensal domiciliar per capita aumenta, em média, 1,4\%. Não se observa, de outra parte, grande variação durante o período e, como a renda média mensal domiciliar per capita cresceu $43 \%$ em termos reais, o investimento em educaçấo pública teve trajetória similar. Se for considerado o investimento conforme o Inep, a participação desse investimento na renda média no período é de 1,6\%. Vale notar, por sua vez, que esse investimento é superior a algumas das transferências de renda de caráter assistencial, como o Bolsa Família e o BPC. Na realidade, juntas, essas duas políticas têm um peso na renda média domiciliar per capita similar ao do investimento em ensino superior público. Efetivamente, segundo os dados da Pesquisa de Orçamentos Familiares (POF) 2017/2018, o Bolsa Família respondia por 0,6\% da renda domiciliar monetária per capita, e о BPC, por 0,7\%. 
TABELA 2

Evolução da renda mensal domiciliar per capita original e com ensino superior - Brasil

\begin{tabular}{|c|c|c|c|}
\hline \multirow[b]{2}{*}{ Ano } & \multicolumn{3}{|c|}{ Renda mensal domiciliar per capita } \\
\hline & $\begin{array}{c}\text { Original } \\
\text { (A) } \\
\text { (R\$ correntes) }\end{array}$ & $\begin{array}{c}\text { Com ensino superior } \\
\text { (B) } \\
\text { (R\$ correntes) }\end{array}$ & $\begin{array}{l}\text { Variação } \\
\text { (B-A/A) } \\
(\%)\end{array}$ \\
\hline 2001 & 297,25 & 301,76 & 1,5 \\
\hline 2002 & 327,09 & 331,87 & 1,5 \\
\hline 2003 & 359,76 & 364,79 & 1,4 \\
\hline 2004 & 388,80 & 393,58 & 1,2 \\
\hline 2005 & 433,86 & 439,67 & 1,3 \\
\hline 2006 & 487,43 & 493,99 & 1,3 \\
\hline 2007 & 524,41 & 531,66 & 1,4 \\
\hline 2008 & 589,14 & 596,33 & 1,2 \\
\hline 2009 & 631,20 & 639,73 & 1,4 \\
\hline 2011 & 754,11 & 766,56 & 1,6 \\
\hline 2012 & 858,35 & 870,02 & 1,4 \\
\hline 2013 & 938,10 & 952,35 & 1,5 \\
\hline 2014 & $1.031,88$ & $1.046,79$ & 1,4 \\
\hline 2015 & $1.056,63$ & $1.072,82$ & 1,5 \\
\hline
\end{tabular}

Fontes: Inep; e microdados da PNAD/IBGE.

Para uma avaliação dos efeitos redistributivos do investimento com ensino superior, consideram-se a renda domiciliar per capita original e a que resulta da adição do investimento em ensino superior público domiciliar per capita à renda. Para comparação entre as estruturas de distribuição dessas rendas, usar indicadores sintéticos de desigualdade, notadamente o Gini, é a escolha mais imediata. Há, contudo, que se levar em consideração que essa comparação não permite avaliar os componentes responsáveis pela mudança distributiva, a incidência ou concentração do investimento em ensino superior, seu peso na renda e as alteraçóes na ordenação da distribuição da renda. ${ }^{9}$

9. Cabe destacar duas limitações da metodologia empregada. Primeiro, atribui-se valor monetário único (uma média) a todo e qualquer aluno que tenha frequentado algum curso de ensino superior público. Sabe-se, porém, que o custo varia entre cursos e que indivíduos de estratos mais privilegiados da população frequentam áreas mais prestigiosas, algumas das quais com custo maior que a média (por exemplo, estudantes do curso de medicina). Segundo, aumentou consideravelmente, no período estudado, a proporção de alunos matriculados em educação a distância (EAD), que têm custos médios mais baixos que os presenciais e nos quais estão sobrerrepresentados indivíduos de estratos sociais mais modestos (por exemplo, estudantes do curso de pedagogia). Não há dados disponíveis que permitam fazer análises levando em conta a distinção entre presencial e EAD, nem entre cursos. 
A valoração da oferta pública de saúde e educação, por meio da aplicação dos valores orçamentários aos beneficiários discriminados em pesquisas domiciliares, é empregada por analistas que estimam os impactos da ação pública por meio dos tributos, das transferências monetárias e de bens pelo setor público. Entre os investigadores que realizaram estimativas sobre os impactos dos gastos públicos em saúde e educação, encontram-se Silveira e Passos (2017), para o caso brasileiro, e Lustig (2016) e Lustig, Pessino e Scott (2014), para países em desenvolvimento, notadamente os latino-americanos, entre os quais está o Brasil. A avaliação restrita à educação superior pública não fora ainda realizada, ou seja, tal esforço é original.

Apresenta-se, a seguir, em termos formais, os principais indicadores que serão reportados na análise da evolução do impacto redistributivo do investimento em ensino superior público: o coeficiente de concentração do investimento e sua contribuição marginal ao Gini e os índices de progressividade de Kakwani e Lerman/Yitzhaki.

Considera-se que a renda $x_{i}$ - posterior ao benefício ou mais amplamente a renda ex post - está ordenada de maneira que:

$x_{i 1} \leq x_{i 2} \leq \cdots \leq x_{i n}$

O índice de Gini dessa distribuição pode ser calculado por meio da expressão:

$$
\begin{aligned}
& G_{x_{i}}=\frac{2}{n \mu_{i}} \operatorname{cov}\left(i, x_{i}\right), \\
& { }_{\operatorname{com}} \mu_{i}=\frac{1}{n} \sum_{n=1}^{n} x_{i n} .
\end{aligned}
$$

Admite-se que a renda $x_{i}$ é formada por duas parcelas: a renda original $\left(x_{0}\right)$ e o investimento em educação superior $(b)$.

$$
x_{i}=\sum_{h=1}^{2} x_{h i}
$$

As médias de cada parcela são respectivamente:

$$
\begin{aligned}
& \mu_{x_{o}}=\frac{1}{n} \sum_{i=1}^{n} x_{o i \mathrm{e}} \\
& \mu_{b}=\frac{1}{n} \sum_{i=1}^{n} b_{i},
\end{aligned}
$$


e as respectivas participaçóes na renda total são:

$$
\begin{aligned}
& \varphi_{x_{o}}=\frac{\mu_{x_{o}}}{\mu}=\frac{\sum_{i=1}^{n} x_{o i}}{\sum_{i=1}^{n} x_{i}} \mathrm{e} \\
& \varphi_{b}=\frac{\mu_{b}}{\mu}=\frac{\sum_{i=1}^{n} b_{i}}{\sum_{i=1}^{n} x_{i}} .
\end{aligned}
$$

Substituindo (3) em (2), obtém-se:

$$
G_{x_{i}}=\frac{2}{n} \sum_{h=1}^{2} \varphi_{h} \frac{1}{\mu_{h}} \operatorname{cov}\left(i, x_{h i}\right) \text {. }
$$

De modo semelhante a (1), pode-se definir as razóes de concentração de cada uma das parcelas como:

$$
\begin{aligned}
C_{X_{O}} & =\frac{2}{n \mu_{x_{o}}} \operatorname{cov}\left(i, x_{o i}\right)=\frac{2}{n} \operatorname{cov}\left(i, \frac{x_{o i}}{\mu_{x_{o}}}\right) \mathrm{e} \\
C_{b} & =\frac{2}{n \mu_{b}} \operatorname{cov}\left(i, b_{i}\right)=\frac{2}{n} \operatorname{cov}\left(i, \frac{b_{i}}{\mu_{b}}\right) .
\end{aligned}
$$

Deve-se levar em consideração, como dito, que as razóes de concentração são definidas com base na ordenação pela renda final.

Como resultado de (7), (8) e (9), tem-se que:

$$
G_{x_{i}}=\varphi_{x_{o}} C_{x_{0}}+\varphi_{b} C_{b}
$$

Podemos avaliar o comportamento do Gini caso ocorra uma variaçáo marginal no valor do benefício. Como visto, o índice de Gini da renda $x_{i}$ (posterior) é:

$$
G_{x_{i}}=\frac{1}{1+\beta} C_{x_{o}}+\frac{\beta}{1+\beta} C_{b}
$$

$\operatorname{com} \beta$ sendo a razão entre o valor do benefício da educação superior (b) e o valor da renda inicial $\left(x_{0}\right)$, ou seja:

$$
\beta=\frac{\sum b}{\sum x_{o}} \text {. }
$$


Supondo-se uma alteração proporcional no valor do benefício, o novo valor pode ser descrito da seguinte forma:

$$
b_{\mathrm{d}}=\theta \beta
$$

$\operatorname{com} \theta=1+\delta$, em que $\delta$ é positivo e arbitrariamente pequeno, a ponto de não causar a reordenação das rendas ex post, o que implica as razóes de concentração $C_{x_{o}}$ e $C_{b}$ continuarem iguais.

O novo valor de $b$ é:

$\beta_{\mathrm{D}}=\theta \beta$.

Assim, o novo índice de Gini da renda ex post é:

$$
\frac{1}{1+\theta \beta} C_{x_{o}}+\frac{\theta \beta}{1+\theta \beta} C_{b}
$$

e, lembrando (11), a variação de $G_{x}$ é:

$$
\Delta G_{x_{i}}=\left(\frac{1}{1+\theta \beta}-\frac{1}{1+\beta}\right) C_{x_{o}}+\left(\frac{\theta \beta}{1+\theta \beta}-\frac{\beta}{1+\beta}\right) C_{b}
$$

Após alguma manipulação algébrica, usando (11), obtemos:

$$
\frac{\Delta G_{x_{i}}}{\theta-1}=\frac{\Delta G_{x_{i}}}{\delta}=\frac{\beta}{1+\theta \beta}\left(C_{b}-G_{x_{i}}\right) \text {. }
$$

Pode-se definir o nível de variação do índice de Gini advindo do incremento marginal do benefício como:

$$
\frac{\Delta G_{x_{i}}}{\delta}=\frac{\beta}{1+\beta}\left(C_{b}-G_{x_{i}}\right) \text {. }
$$

Desse modo, a contribuição marginal da educação superior é igual à diferença entre o coeficiente de concentração do benefício e o índice de Gini da renda com o benefício ponderada pela participação na renda posterior. 
No caso do índice de progressividade de Kakwani, vamos admitir que as pessoas estâo ordenadas conforme os valores da renda inicial, isto é:

$$
x_{o 1} \leq x_{o 2} \leq \cdots \leq x_{o n}
$$

Então o índice de Gini da renda original, ou seja, anterior ao benefício é:

$$
G_{x_{o}}=\frac{2}{n \mu_{o}} \operatorname{cov}\left(i, x_{o}\right)
$$

e recordando que a razão de concentração do benefício é:

$$
C_{b}=\frac{2}{n \mu_{b}} \operatorname{cov}\left(i, b_{i}\right),
$$

com as observaçóes ordenadas segundo a renda original $\left(x_{0}\right)$ diferentemente de (9).

Seja $C_{x_{i}}$ a razão de concentração da renda após a concessão do benefício e seja $G_{x_{i}}$ o respectivo índice de Gini, o índice de progressividade de Kakwani é definido como:

$$
I_{K}=G_{x_{o}}-C_{b}
$$

e pode-se demonstrar que a alteração no índice de Gini devida ao benefício é:

$$
G_{x_{o}}-G_{x_{i}}=\frac{\beta}{1+\beta} I_{K}-\left(. G_{x_{i}}-C_{x_{i}}\right) .
$$

A expressão (19) mostra que a mudança na desigualdade decorre da progressividade do benefício, ponderado por sua participação na renda posterior, e de alteraçôes no ordenamento das famílias, consubstanciado no segundo termo da expressão.

Se o benefício não causar reordenação das rendas, tem-se que $G_{x_{i}}=C_{x_{i} \text { e a mu- }}$ dança no índice de Gini $\left(G_{x_{o}}-G_{x_{i}}\right)$ é proporcional ao índice de progressividade $I_{K}$, com o efeito sendo tanto maior for a importância do benefício $-\left(\frac{\beta}{1+\beta}\right)$.

Caso se tenha algum efeito de reordenação, esse reduzirá o potencial redistributivo, uma vez que o índice de Gini de uma distribuição sempre é igual ou maior do que a razão de concentração para uma ordenação distinta daquela própria variável. $\mathrm{Ou}$ seja, o segundo termo será sempre positivo e, assim, reduzirá o efeito redistributivo do benefício, caso esse tenha incidência progressiva. 
Vale destacar que, no caso dos tributos, as alteraçóes no ordenamento são marginais ou de pequena envergadura, diferentemente dos benefícios náo universais, como com a educação superior.

Pode-se, de modo similar, analisar os efeitos redistributivos segundo sua concentração e seus efeitos de reordenamento com base na renda posterior. Nesse caso, deduz-se, de modo análogo ao desenvolvido anteriormente, que:

$$
G_{x_{o}}-G_{x_{i}}=\beta\left(G_{x_{i}}-C_{b}\right)+\left(G_{x_{o}}-C_{x_{o}}\right)
$$

Decidiu-se nomear como índice de progressividade dos benefícios de Lerman e Yitzhaki - seguindo Hoffmann (2007) e Silveira (2008) - a diferença entre o Gini da renda posterior ao benefício e o coeficiente de concentração do benefício pela ordenação segundo a renda final $x_{i}$.

$$
I_{L Y}=G_{x_{i}}-C_{b}
$$

Substituindo em (20), segue-se que:

$$
G_{x_{o}}-G_{x_{i}}=\beta I_{L Y}+\left(G_{x_{o}}-C_{x_{o}}\right) \text {. }
$$

Essa expressão mostra, mais uma vez, como a mudança no índice de Gini depende de uma medida de progressividade e de um efeito de reordenaçáo. Efeito este que sempre terá sinal positivo e se somará aos efeitos redistributivos de um benefício progressivo ou atenuará o de um benefício regressivo.

Vale notar que o indicador de progressividade de Lerman/Yitzhaki ponderado pela participaçáo na renda pretérita é o valor com sinal trocado da contribuição marginal ao Gini.

Valores positivos para os índices significam progressividade na incidência (Kakwani) e na concentração (Lerman/Yitzhaki) e valores negativos, regressividade. Como tais índices resultam das diferenças entre o Gini e os coeficientes de concentração, valores próximos de 0 indicam neutralidade e, quanto mais se aproximam da unidade ou a superam - em módulo -, mais progressivos ou regressivos se apresentam. 


\subsection{Evolução da distribuição do investimento em ensino superior público e seus efeitos redistributivos}

De modo semelhante ao que foi apontado na análise da participação no alunado público superior por quintos de renda domiciliar per capita (subseçáo 2.2), os dados relativos à divisão do investimento com educação superior pública por grupos de renda mostram um processo de ampliaçáo da participaçáo dos mais pobres nesse investimento, notadamente após 2009 (gráfico 10). Enquanto entre 2001 e 2006 a participação dos $80 \%$ mais pobres teve um aumento pouco expressivo, passando de $42 \%$ para $48 \%$, entre 2006 e 2015 o aumento foi significativo, atingindo 59\%, em 2011, e quase dois terços do investimento no último ano da série.

\section{GRÁFICO 10}

Evolução da participação de estratos de renda selecionados no investimento em educação de ensino superior

(Em \%)

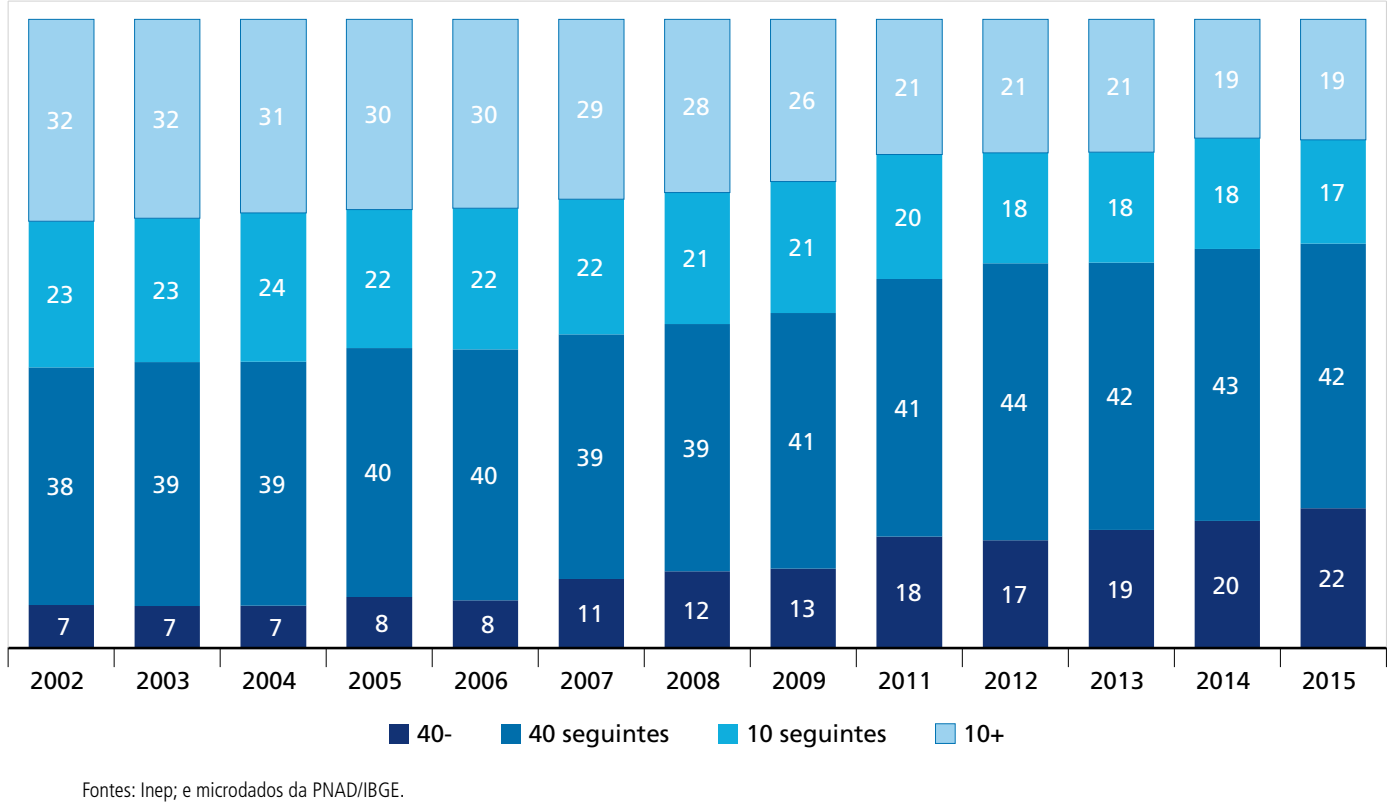

Esse processo de ampliação se concentra nos $40 \%$ mais pobres que, de uma participação marginal ao redor de $7 \%$ na primeira metade da década de 2000 , alcança um patamar de $12 \%$ no final dessa década, chegando a $18 \%$ em 2011 e próximo de um quarto em 2015. Com isso, os 20\% mais ricos que eram majoritários nos anos 2000 , com a participação sendo reduzida de $58 \%$ para $47 \%$, passaram a se apropriar de $36 \%$ 
em 2015, uma redução de 22 pontos percentuais em quinze anos. Os dois grupos considerados, os $10 \%$ mais ricos e os $10 \%$ logo abaixo, tiveram perdas expressivas, com os mais ricos perdendo relativamente mais. Em 2015, ambos os estratos se apropriam de parcelas semelhantes. Vale observar que o componente demográfico é um importante determinante nessa distribuição, uma vez que, nos estratos superiores de renda, a população é mais idosa e é menor a presença de jovens e adultos, público do ensino superior.

Mas não resta dúvida que o aumento da participação dos 40\% mais pobres no investimento em ensino superior público é revelador do grande avanço no acesso à universidade pelos mais pobres. Seus impactos redistributivos devem ser avaliados de vários ângulos. A evolução da distribuição do investimento segundo estratos de renda e do índice de Gini com e sem o benefício, analisada a seguir, mostram os avanços redistributivos, com a avaliação pelos coeficientes de concentração e pelos indicadores de progressividade fornecendo uma análise mais acurada.

Os dados da tabela 3 mostram que a educação superior afeta marginalmente o Gini, o que decorre, como será apresentado, do perfil de sua incidência e do pequeno peso que tem diante da renda. Chama a atenção, no entanto, a alteração na diferença entre o Gini da renda original e depois do investimento com educaçáo pública superior no final do período. Se até 2011 o Gini da renda considerando o investimento em ensino superior era levemente superior à renda original, passa a ser igual no biênio 2012/2013, e torna-se menor no biênio 2014/2015. Ou seja, quando adicionado à renda, o investimento com educação superior pública contribui para reduzir levemente o índice de Gini. Dado o desenho da pesquisa, pode-se inferir que o investimento em educação superior pública, quando considerada como fonte de renda, não tem efeitos sobre o Gini considerando o intervalo de confiança.

TABELA 3

Evolução do índice de Gini da renda domiciliar per capita original e com ensino superior - Brasil

\begin{tabular}{lccc}
\hline Ano & Renda original & Renda com ensino superior & Variação \\
\hline 2001 & 0,5940 & 0,5956 & 0,0016 \\
2002 & 0,5875 & 0,5888 & 0,0014 \\
2003 & 0,5810 & 0,5821 & 0,0011 \\
2004 & 0,5705 & 0,5716 & 0,0010 \\
2005 & 0,5676 & 0,5687 & 0,0011 \\
\hline & & & (Continua)
\end{tabular}




\begin{tabular}{lccc} 
(Continuação) & & & \\
\hline Ano & Renda original & Renda com ensino superior & Variação \\
\hline 2006 & 0,5608 & 0,5620 & 0,0012 \\
2007 & 0,5539 & 0,5548 & 0,0009 \\
2008 & 0,5440 & 0,5446 & 0,0006 \\
2009 & 0,5400 & 0,5407 & 0,0007 \\
2011 & 0,5292 & 0,5296 & 0,0004 \\
2012 & 0,5262 & 0,5262 & 0,0000 \\
2013 & 0,5250 & 0,5250 & 0,0000 \\
2014 & 0,5152 & 0,5150 & $-0,0002$ \\
2015 & 0,5145 & 0,5143 & $-0,0002$ \\
\hline
\end{tabular}

Fontes: Inep; e microdados da PNAD/IBGE.

O gráfico 11 mostra a curva de Lorenz da renda original e os coeficientes de incidência desse investimento com base na renda original - definiu-se incidência do investimento para diferenciar do coeficiente de concentração pela ordenação segundo a renda posterior. Fica evidente que partimos de uma incidência neutra - ou até mesmo regressiva -, em 2001, para uma situação de incidência progressiva, em 2015. O coeficiente de concentraçáo do investimento em ensino superior público se reduziu muito, ficando bastante inferior ao Gini da renda original. E há de sublinhar que o Gini - Lorenz - da renda original reduziu-se constantemente no período, ou seja, a incidência do investimento tornou-se menos desigual que a observada na renda. Fica, portanto, a pergunta: por que o índice de Gini varia táo pouco se o perfil de incidência do investimento se torna claramente progressivo? É possível que o pequeno peso na renda atenue a progressividade da incidência, que, ademais, é mitigado pelos efeitos de reordenamento. ${ }^{10}$

10. Em anexo encontram-se duas tabelas relativas a cada uma das rendas (original e posterior ao investimento em ensino superior público) com seu respectivo índice de Gini, a participação do benefício e os coeficientes do benefício e da outra renda. Com esses dados, calcula-se os índices de progressividade de Kakwani e de Lerman/Yitzhaki e os efeitos de reordenamento. 
GRÁFICO 11

Curvas de Lorenz da renda original e da incidência do investimento (com base na renda original) para anos selecionados

$11 \mathrm{~A}-2001$

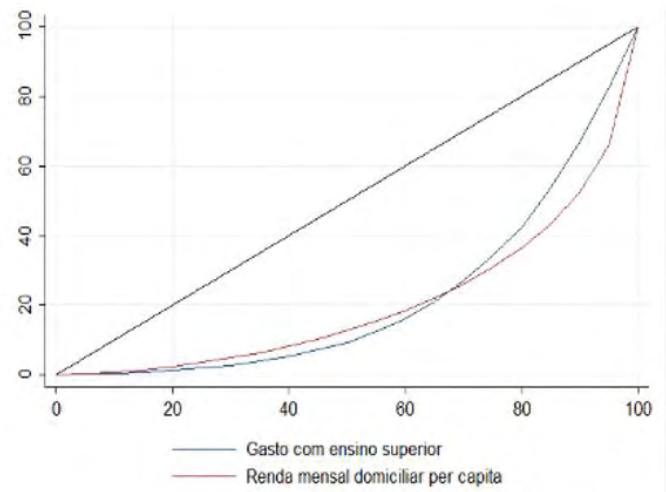

$11 C-2012$

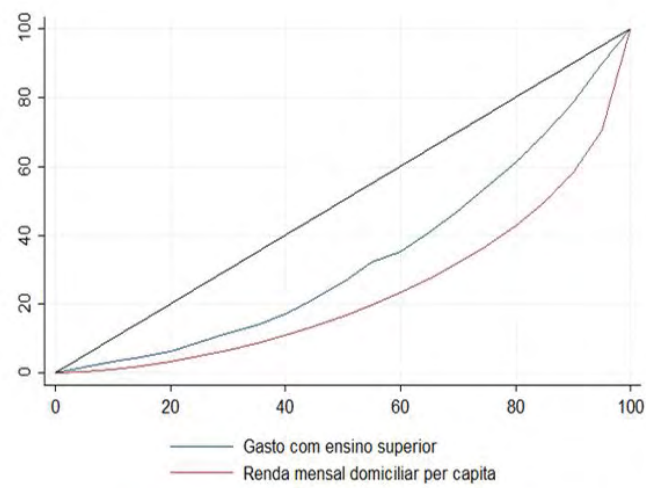

$11 B-2006$

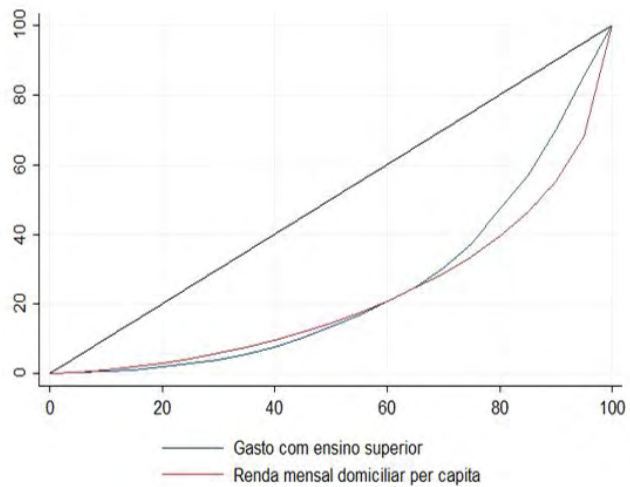

$11 D-2015$

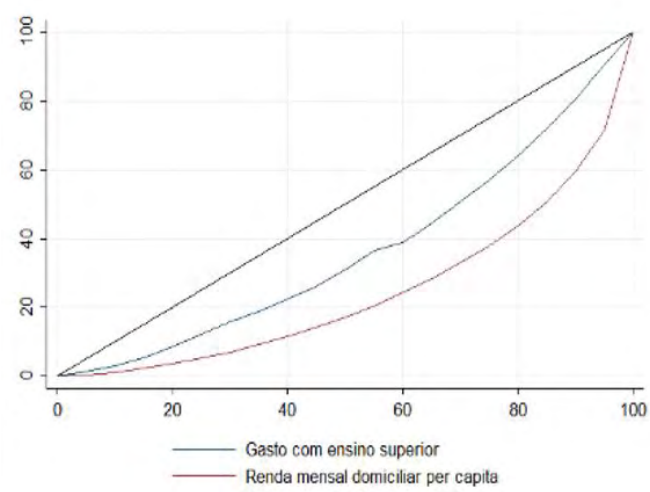

Fontes: Inep; e microdados da PNAD/IBGE.

Obs.: Figura cujos leiaute e textos não puderam ser padronizados e revisados em virtude das condições técnicas dos originais (nota do Editorial).

Na tabela 4, são apresentados o índice de Kakwani, o impacto da progressividade, o efeito de reordenamento e o resultado medido pela diferença do Gini da renda original e da posterior à inclusão do investimento com educação superior. Lembrando que o efeito de reordenamento sempre é de incremento da desigualdade. Nota-se que, na maior parte do período, esse efeito dominou sobre a incidência do benefício, que passou a ser progressiva. O índice de progressividade de Kakwani é sempre positivo, sendo inferior a 0,1 entre 2001 e 2007, passando, então a crescer, notadamente, entre 2011 e 2015. Tal indicador sintetiza os movimentos observados nos gráficos 10 e 11 . O impacto da progressividade é o resultado da ponderação do índice de Kakwani pela participação do benefício na renda posterior, tendo sido inferior aos efeitos de reordenamento, entre 2001 e 2011, e levemente superior nos últimos dois anos do período analisado. 
Importante observar como a progressividade da incidência do benefício, com a expansão do alunado, implicou uma redução dos impactos regressivos que o reordenamento exige.

TABELA 4

Evolução do índice de Kakwani, do impacto da incidência do benefício, dos efeitos de reordenamento e do resultado final na desigualdade - Brasil

\begin{tabular}{cccccc}
\hline Ano & Índice de Kakwani & $\begin{array}{c}\text { Participação na renda } \\
\text { posterior (\%) }\end{array}$ & Impacto da progressividade & $\begin{array}{c}\text { Efeito de } \\
\text { reordenamento }\end{array}$ & $\begin{array}{c}\text { Resultado distributivo final } \\
\text { (Gini antes - Gini depois) }\end{array}$ \\
\hline 2001 & 0,0337 & 1,50 & 0,0005 & 0,0021 & $-0,0015$ \\
2002 & 0,0475 & 1,44 & 0,0007 & 0,0020 & $-0,0014$ \\
2003 & 0,0524 & 1,38 & 0,0007 & 0,0018 & $-0,0011$ \\
2004 & 0,0386 & 1,21 & 0,0005 & 0,0015 & $-0,0011$ \\
2005 & 0,0594 & 1,32 & 0,0008 & 0,0018 & $-0,0011$ \\
2006 & 0,0480 & 1,33 & 0,0006 & 0,0018 & $-0,0012$ \\
2007 & 0,0889 & 1,36 & 0,0012 & 0,0021 & $-0,0009$ \\
2008 & 0,1028 & 1,21 & 0,0012 & 0,0018 & $-0,0006$ \\
2009 & 0,1121 & 1,33 & 0,0015 & 0,0022 & $-0,0007$ \\
2011 & 0,1887 & 1,62 & 0,0031 & 0,0035 & $-0,0004$ \\
2012 & 0,1993 & 1,34 & 0,0027 & 0,0027 & 0,0000 \\
2013 & 0,2129 & 1,50 & 0,0032 & 0,0032 & 0,0000 \\
2014 & 0,2264 & 1,42 & 0,0032 & 0,0030 & 0,0002 \\
2015 & 0,2432 & 1,51 & 0,0037 & 0,0034 & 0,0002 \\
\hline
\end{tabular}

Considerando que os efeitos de reordenamento reduzem o impacto distributivo de um benefício de incidência progressiva, isso pode significar um aumento da desigualdade. O exemplo mais evidente é com as aposentadorias e pensôes do Regime Próprio de Previdência Social (RPPS), que apresentam índice de Kakwani positivo e relativamente elevado, isso porque os beneficiários das aposentadorias, em sua maioria, contam somente com essa fonte de renda, ou seja, contam com renda anterior ao benefício nula. Pelo valor médio do benefício, essas pessoas são realocadas para o topo da distribuição. No caso do ensino superior público, nota-se como os efeitos de reordenamento são expressivos e inclusive mudaram de patamar. Em parte, isso se deve ao acesso dos $40 \%$ mais pobres à educação superior, pois a presença de um filho na universidade implica a mudança de nível de renda da família na distribuição da renda com a atribuição de um valor monetário ao uso do serviço da educação superior. Exemplificando, em 2015, a renda média dos $40 \%$ mais pobres era de $\mathrm{R} \$ 302$, enquanto a renda do percentil 40 era $\mathrm{R} \$ 538$, e, dividindo o investimento médio mensal por aluno de R\$ 1.935 pelo tamanho médio da família $(3,2)$ chega-se a um acréscimo de renda de $200 \%$ e $112 \%$, respectivamente. 
Vale, então, analisar a progressividade do investimento em ensino superior público pela renda posterior, avaliando a evolução do coeficiente de concentração e da contribuição marginal à desigualdade, bem como o índice de Lerman/Yitzhaki. Nesse contexto, é importante relembrar que o impacto da progressividade é o índice ponderado pela participação na renda posterior, sendo o mesmo valor com sinal contrário da contribuição marginal ao Gini da renda posterior. De maneira ilustrativa, pode-se dizer que a contribuição marginal aponta o que ocorreria se fosse concedido um real a mais no índice de Gini, assim como o impacto da progressividade - ou seja, Kakwani ponderado pela participação na renda posterior - indica o impacto na desigualdade do primeiro real concedido. Nesses casos, os efeitos de reordenamento não se fazem presentes.

Como se vê na tabela 5, o índice de Lerman/Yitzhaki sempre é negativo, ou seja, o próximo real concedido tem um impacto regressivo, mas esse valor vem se aproximando de zero, em direção à neutralidade. Ademais, os efeitos de reordenamento, que no caso da renda posterior são sempre progressivos, superaram, no último biênio, a regressividade da concentração do benefício, implicando uma diminuição do Gini indicado pelo sinal positivo na última coluna da tabela, dado ser a diferença entre o Gini da renda prévia com o da renda posterior.

\section{TABELA 5}

Evolução do índice de Lerman/Yitzhaki, do impacto da concentração do benefício, dos efeitos de reordenamento e do resultado final na desigualdade - Brasil

\begin{tabular}{cccccc}
\hline Ano & Índice de Lerman/Yitzhaki & $\begin{array}{c}\text { Participação na renda } \\
\text { original (\%) }\end{array}$ & Impacto concentração & Efeito de reordenamento & $\begin{array}{c}\text { Resultado distributivo } \\
\text { final } \\
\text { (Gini antes - Gini } \\
\text { depois) }\end{array}$ \\
\hline 2001 & $-0,1902$ & 1,50 & $-0,0028$ & 0,0013 & $-0,0015$ \\
2002 & $-0,1861$ & 1,46 & $-0,0027$ & 0,0013 & $-0,0014$ \\
2003 & $-0,1694$ & 1,40 & $-0,0024$ & 0,0012 & $-0,0011$ \\
2004 & $-0,1731$ & 1,23 & $-0,0021$ & 0,0011 & $-0,0011$ \\
2005 & $-0,1760$ & 1,34 & $-0,0024$ & 0,0013 & $-0,0011$ \\
2006 & $-0,1823$ & 1,35 & $-0,0025$ & 0,0013 & $-0,0012$ \\
2007 & $-0,1698$ & 1,38 & $-0,0023$ & 0,0015 & $-0,0009$ \\
2008 & $-0,1572$ & 1,22 & $-0,0019$ & 0,0013 & $-0,0006$ \\
2009 & $-0,1713$ & 1,35 & $-0,0023$ & 0,0016 & $-0,0007$ \\
2011 & $-0,1718$ & 1,65 & $-0,0028$ & 0,0024 & $-0,0005$ \\
2012 & $-0,1384$ & 1,36 & $-0,0019$ & 0,0019 & 0,0000 \\
2013 & $-0,1501$ & 1,52 & $-0,0023$ & 0,0022 & 0,0000 \\
2014 & $-0,1321$ & 1,44 & $-0,0019$ & 0,0022 & 0,0003 \\
2015 & $-0,1412$ & 1,53 & $-0,0022$ & 0,0024 & 0,0002 \\
\hline
\end{tabular}


Fica claro, portanto, que, ao longo dos anos, a incidência se tornou mais progressiva, com o Kakwani passando de valores próximos a zero para um patamar de 0,25. $\mathrm{O}$ indicador pela renda posterior, por sua vez, mostra-se regressivo em todo o período, mas se observa uma atenuação em direção à neutralidade, segundo o índice de Lerman/ Yitzhaki. Vale notar ainda que essa evolução se verifica em um cenário de contínua queda da desigualdade da renda anterior. Ou seja, a educaçáo superior mais do que acompanhou a melhora distributiva, deixando de implicar aumento no índice de Gini na renda com o benefício e passando a ser neutra.

Náo se pode afirmar, no momento atual, que o ensino público superior seja concentrador de renda, mas se pode afirmar que ocorreram alteraçóes profundas em direção à progressividade em seu perfil de incidência/prevalência com a incorporação dos mais pobres na universidade pública na última década.

\section{CONSIDERAÇÕES FINAIS}

Ainda é comum o argumento de que o investimento público no ensino superior é regressivo, por ser destinado às famílias que estáo nos estratos mais elevados da distribuição de renda. Não obstante, as últimas décadas presenciaram o surgimento de diversas políticas públicas inclusivas para a educação superior que resultaram em uma mudança significativa no perfil dos estudantes das universidades públicas brasileiras.

$\mathrm{Na}$ linha da literatura recente, a despeito de que, ao final do período analisado, em 2015, parcela considerável do investimento público em educação superior ainda era apropriada pelos estratos superiores de renda, este estudo destaca que é inegável que a expansão do ensino superior foi acompanhada de uma maior democratização no acesso, especialmente no período 2005-2015. Quem acolheu maior proporção de grupos não privilegiados na composição de seu alunado foram as universidades públicas.

A análise do efeito redistributivo do investimento em ensino superior público revela que houve uma mudança significativa em sua incidência ao longo da distribuição de renda. Entre 2001 e 2015, esse investimento passa a beneficiar cada vez mais as famílias nos estratos mais pobres e, assim, deixa de contribuir para a elevaçáo da desigualdade. 
A queda na regressividade do investimento em educação superior não significa que não haja questóes a serem resolvidas no sistema de educação superior. Para reduzir as desigualdades de oportunidades ainda observadas, é preciso manter e aprofundar o processo de inclusão social no acesso. Há ainda novas questôes que devem ser consideradas tanto por pesquisadores quanto por formuladores de políticas, tais como: a permanência dos jovens de origem socioeconômica desfavorecida ao longo do curso; o acesso desses jovens a cursos tradicionalmente associados à elite, como medicina, direito e engenharia; e a melhoria na qualidade dos cursos mantendo os custos sob controle.

\section{REFERÊNCIAS}

BANCO MUNDIAL. Um ajuste justo: análise da eficiência e equidade do gasto público no Brasil. Washington: Banco Mundial, 2017.

BRITO, M. M. A. A dependência na origem: desigualdades no sistema educacional brasileiro e a estruturaçáo social das oportunidades. 2014. Tese (Doutorado) - Universidade de São Paulo, São Paulo, 2014.

CARVALHO, J. C. B. "Educação/Education", Brasil em números. Brazil in Figures, v. 11, p. 118-134, 2003.

CARVALHO, M.; WALTENBERG, F. D. Desigualdade de oportunidades no acesso ao ensino superior no Brasil: uma comparação entre 2003 e 2013. Economia Aplicada, v. 19, n. 2, p. 369-396, 2015.

CASEIRO, L. C. Z. Desigualdade de acesso à educaçáo superior no Brasil e o Plano Nacional de Educaçáo. p. 40, 2016. (Série PNE em Movimento, n. 3).

CATALDO, B. Higher Education Funding in Brazil and the Income Contingent Loans Alternative. 2019. Dissertaçâo (Mestrado) - Universidade Federal Fluminense, Rio de Janeiro, 2019.

CGU comprova que 90\% das obras de expansão foram concluídas. Portal MEC, 27 abr. 2015. Disponível em: <https://bit.ly/3qzvTQJ>. Acesso em: 4 jul. 2020.

DE FAVERI, D. B.; PETTERINI, F. C.; BARBOSA, M. P. Uma avaliação do impacto da política de expansão dos institutos federais nas economias dos municípios brasileiros. Planejamento e Políticas Públicas, n. 50, 2018.

FONAPRACE - FÓRUM NACIONAL DE PRÓ-REITORES DE ASSUNTOS COMUNITÁRIOS E ESTUDANTIS. V Pesquisa Nacional de Perfil Socioeconômico e Cultural dos (as) Graduandos (as) das Ifes - 2018. Brasília: Fonaprace, 2019. 318p. 
FRANCIS, A. M.; TANNURI-PIANTO, M. Using Brazil's racial continuum to examine the short-term effects of affirmative action in higher education. Journal of Human Resources, v. 47, n. 3, p. 754-784, 2012.

FRANCO, A. M. D. P.; CUNHA, S. Perfil socioeconômico dos graduandos das Ifes. Radar: tecnologia, produçáo e comércio exterior, n. 47, 2017.

HOFFMAN, R. Medindo a regressividade das transferências. In: BARROS, R. P.; FOGUEL, M. N.; ULYSSEA, G. (Orgs.). Desigualdade de renda no Brasil: uma análise da queda recente. Brasília: Ipea, 2007. v. 2.

IBGE - INSTITUTO BRASILEIRO DE GEOGRAFIA E ESTATÍSTICA. Coordenação de População e Indicadores Sociais. Síntese de indicadores sociais: uma análise das condições de vida da população brasileira. Estudos e Pesquisas: Informaçáo Demográfica e Socioeconômica, n. 36, 2016.

LUSTIG, N. Inequality and fiscal redistribution in middle income countries: Brazil, Chile, Colombia, Indonesia, Mexico, Peru and South Africa. Journal of Globalization and Development, v. 7, n. 1, p. 17-60, 2016. Disponível em: <https://bit.ly/36srrf9>. Acesso em: 20 jan. 2021.

LUSTIG, N.; PESSINO, C.; SCOTT, J. The impact of taxes and social spending on inequality and poverty in Argentina, Bolivia, Brazil, Mexico, Peru, and Uruguay: introduction to the special issue. Public Finance Review, v. 42, n. 3, p. 287-303, 2014. Disponível em: <https:// bit.ly/368Wo7C>. Acesso em: 20 jan. 2021.

MCCOWAN, T. Expansion without equity: an analysis of current policy on access to higher education in Brazil. Higher education, v. 53, n. 5, p. 579-598, 2007.

MENDES JUNIOR, A. A. F.; SOUZA, A. D. M. E.; WALTENBERG, F. D. Affirmative action and access to higher education in Brazil: the significance of race and other social factors. Journal of Latin American Studies, v. 48, n. 2, p. 301-334, 2016.

NIQUITO, T. W.; RIBEIRO, F. G.; PORTUGAL, M. S. Impacto da criação das novas universidades federais sobre as economias locais. Planejamento e Políticas Públicas, n. 51, 2018.

OLIVEIRA, A. L. M. Educação superior brasileira no início do século XXI: inclusão interrompida? 2019. Tese (Doutorado) - Instituto de Economia, Universidade Estadual de Campinas, Campinas, 2019.

OSÓRIO, A. C. N. "Educação/Education”, Brasil em números. Brazil in Figures, v. 25, p. 149-171, 2017.

ROCHA, R. H. et al. A relação entre o ensino superior público e privado e a renda e emprego nos municípios brasileiros. Pesquisa e Planejamento Econômico, v. 47, n. 3, dez. 2017.

SALATA, A. Ensino Superior no Brasil das últimas décadas: redução nas desigualdades de acesso? Tempo Social, v. 30, n. 2, p. 219-253, 2018. 
SENKEVICS, A. S.; CARVALHO, M. P. Novas e velhas barreiras à escolarização da juventude. Estudos Avançados, v. 34, n. 99, p. 333-352, 2020.

SIMÓES, A. A. Acesso à educação básica e sua universalização. Cadernos de Estudos e Pesquisas em Políticas Educacionais, v. 2, p. 56, 2019.

SILVEIRA, F. G. Tributaçáo, previdência e assistência sociais: impactos distributivos. 2008. Tese (Doutorado) - Universidade Estadual de Campinas, Campinas, 2008.

VILELA, L.; MENEZES-FILHO, N.; TACHIBANA, T. Y. As cotas nas universidades públicas diminuem a qualidade dos alunos selecionados? Simulações com dados do Enem. Centro de Políticas Públicas Insper, n. 17, v. 46, 2016. 

Ipea - Instituto de Pesquisa Econômica Aplicada

\title{
EDITORIAL
}

\section{Chefe do Editorial}

Reginaldo da Silva Domingos

\section{Assistentes da Chefia}

Rafael Augusto Ferreira Cardoso

Samuel Elias de Souza

\section{Supervisão}

Camilla de Miranda Mariath Gomes

Everson da Silva Moura

\section{Editoração}

Aeromilson Trajano de Mesquita

Anderson Silva Reis

Cristiano Ferreira de Araújo

Danilo Leite de Macedo Tavares

Jeovah Herculano Szervinsk Junior

Leonardo Hideki Higa

\section{Capa}

Danielle de Oliveira Ayres

Flaviane Dias de Sant'ana

\section{Projeto Gráfico}

Renato Rodrigues Bueno

The manuscripts in languages other than Portuguese published herein have not been proofread.

\author{
Livraria Ipea \\ SBS - Quadra 1 - Bloco J - Ed. BNDES, Térreo \\ 70076-900 - Brasília - DF \\ Tel.: (61) 2026-5336 \\ Correio eletrônico: livraria@ipea.gov.br
}



Composto em adobe garamond pro 12/16 (texto) Frutiger 67 bold condensed (títulos, gráficos e tabelas) Brasília-DF 



\section{Missão do Ipea}

Aprimorar as políticas públicas essenciais ao desenvolvimento brasileiro por meio da produção e disseminação de conhecimentos e da assessoria ao Estado nas suas decisões estratégicas.

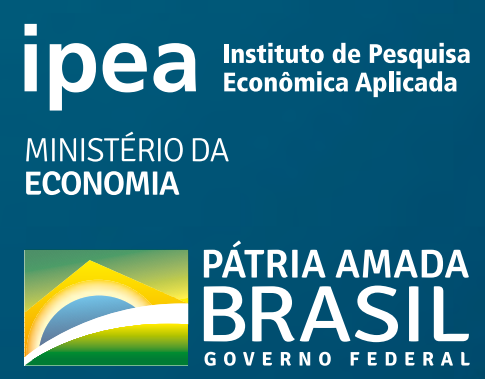

